\title{
Ammonia production, excretion, toxicity, and defense in fish: a review
}

\author{
Yuen K. Ip ${ }^{1 *}$, and Shit F. Chew ${ }^{2}$ \\ Department of Biological Sciences, National University of Singapore, Singapore, Republic of Singapore \\ 2 Natural Sciences and Science Education, National Institute of Education, Nanyang Technological University, Singapore, Republic of Singapore
}

Edited by:

Shigehisa Hirose, Tokyo Institute of Technology, Japan

Reviewed by:

Jim Ballantyne, University of Guelph,

Canada

Jonathan M. Wilson, CIMAR, Portugal

*Correspondence:

Yuen K. Ip, Department of Biological Sciences, National University of

Singapore, Kent Ridge, Singapore

117543, Republic of Singapore.

e-mail:dbsipyk@nus.edu.sg
Many fishes are ammonotelic but some species can detoxify ammonia to glutamine or urea. Certain fish species can accumulate high levels of ammonia in the brain or defense against ammonia toxicity by enhancing the effectiveness of ammonia excretion through active $\mathrm{NH}_{4}^{+}$ transport, manipulation of ambient $\mathrm{pH}$, or reduction in ammonia permeability through the branchial and cutaneous epithelia. Recent reports on ammonia toxicity in mammalian brain reveal the importance of permeation of ammonia through the blood-brain barrier and passages of ammonia and water through transporters in the plasmalemma of brain cells. Additionally, brain ammonia toxicity could be related to the passage of glutamine through the mitochondrial membranes into the mitochondrial matrix. On the other hand, recent reports on ammonia excretion in fish confirm the involvement of Rhesus glycoproteins in the branchial and cutaneous epithelia. Therefore, this review focuses on both the earlier literature and the up-to-date information on the problems and mechanisms concerning the permeation of ammonia, as $\mathrm{NH}_{3}, \mathrm{NH}_{4}^{+}$or protonneutral nitrogenous compounds, across mitochondrial membranes, the blood-brain barrier, the plasmalemma of neurons, and the branchial and cutaneous epithelia of fish. It also addresses how certain fishes with high ammonia tolerance defend against ammonia toxicity through the regulation of the permeation of ammonia and related nitrogenous compounds through various types of membranes. It is hoped that this review would revive the interests in investigations on the passage of ammonia through the mitochondrial membranes and the blood-brain barrier of ammonotelic fishes and fishes with high brain ammonia tolerance, respectively.

Keywords: ammonia, ammonia excretion, ammonia toxicity, ammonia transporter, fish, nitrogen metabolism

\section{INTRODUCTION}

There are many good reasons to study ammonia production and excretion in fish because of its ecological and environmental relevance. Besides, many fish species are of ornamental, aquacultural, and economical values, and ammonia toxicity can be a major issue that leads to mass mortality under unfavorable aquacultural conditions. However, the intensity of studies on mechanisms of ammonia toxicity in fish is far lower than that in mammals. Interests in studying ammonia toxicity in mammals arise from the fact that liver failure in human leads to the development of neurological abnormalities collectively referred to as hepatic encephalopathy, and ammonia is a key neurotoxin implicated in this condition (see Häussinger and Schliess, 2008; Lemberg and Fernandez, 2009 for reviews). More recent studies in mammals have implicated oxidative stress and mitochondrial permeability transition in the mechanism of ammonia neurotoxicity (Norenberg et al., 2005; Jayakumar et al., 2006; Pichili et al., 2007; Reddy et al., 2009; Görg et al., 2010; Häussinger and Görg, 2010). The mitochondrial permeability transition involves the opening of a pore in the inner mitochondrial membrane that leads to a collapse of ionic gradients, resulting in mitochondrial dysfunction. In the case of ammonia neurotoxicity, the mitochondrial permeability transition could be related to the permeation of glutamine through the inner mitochondrial membrane and the production of ammonia through glutaminase in the mitochondrial matrix of astrocytes (Albrecht and Norenberg,
2006). It has been established that several fish species can tolerate high levels of ammonia and/or glutamine in the brain (see Ip et al., 2001b, 2004a,b; Chew et al., 2006b for reviews), but it is uncertain how ammonia and glutamine permeation through the blood-brain barrier of, and plasmalemma and mitochondrial membranes of brain cells in, these fishes are regulated. Furthermore, studies on ammoniagenesis of ammonotelic fishes revealed that ammonia production occurred mainly in the liver mitochondrial matrix (Walton and Cowey, 1977; Campbell et al., 1983; Campbell, 1997), but how ammonia exits the membranes of the liver mitochondria is an enigma. It was assumed that ammonia would permeate the inner mitochondrial membrane as $\mathrm{NH}_{3}$, but such an operation would lead to the disruption of the proton gradient. This could be the reason why ammonia has to be converted into citrulline and glutamine, which are proton-neutral nitrogenous molecules, before exiting the liver mitochondria of ureogenic and uricogenic animals, respectively (Campbell, 1997). On the other hand, excretion of ammonia occurs mainly through the gills of fish, and earlier notions also prescribed that ammonia could permeate the branchial epithelium as $\mathrm{NH}_{3}$ (see Wilkie, 2002 for a review). However, recent studies reveal that ammonia excretion through fish gills can involve transporters (see Weihrauch et al., 2009; Wright and Wood, 2009 for reviews), which affirms the possibility of the presence of ammonia transporter in the inner membrane of liver mitochondria of ammonotelic fishes. Therefore, this review focuses on both the earlier 
literature and the up-to-date information on the problems and mechanisms concerning the permeation of ammonia, as $\mathrm{NH}_{3}, \mathrm{NH}_{4}^{+}$ or proton-neutral nitrogenous compounds, across mitochondrial membranes, the blood-brain barrier, the plasmalemma of neurons, and the branchial and cutaneous epithelia of fish. Efforts have also been made to examine the relationships between the permeation of ammonia through various types of biomembrane and the high tolerance of certain fish species to ammonia toxicity.

\section{PRODUCTION AND EXCRETION OF AMMONIA IN FISH AMMONIA PRODUCTION}

Dietary protein is a major source of amino acids in animals. The intestines of carnivorous fishes are adapted to process diets that are high in protein and low in carbohydrate (Buddington et al., 1997). Karlsson et al. (2006) determined changes in plasma concentrations of free amino acids and their metabolites in preand post-hepatic blood following a single meal in rainbow trout (Oncorhynchus mykiss), and confirmed that amino acids could be metabolized in the intestine before they reached the liver. The plasma ammonia level in the hepatic portal vein was higher than that in the dorsal aorta, and the difference between the two blood sampling sites increased during amino acid absorption after a meal. Thus, Karlsson et al. (2006) concluded that deamination of certain amino acids occurred in the intestine of the rainbow trout after feeding. In support of the conclusion of Karlsson et al. (2006), Tng et al. (2008) reported that postprandial amino acid metabolism indeed occurred in the intestine of juvenile Oxyeleotris marmorata. The major amino acid accumulated in the intestine and liver of juvenile O. marmorata after feeding was glutamate, and feeding led to a significant increase in glutamate dehydrogenase $(\mathrm{GDH})$ activities in the intestine and liver of O. marmorata, which could lead to a high retention of the ingested nitrogen for somatic growth. Consequently, only $33 \%$ of the ingested nitrogen was excreted during the $24 \mathrm{~h}$ post-feeding period, and the brain was effectively prevented from exposure to postprandial ammonia toxicity (Tng et al., 2008).

Animals cannot store excess amino acids, unlike carbohydrates and lipids which can be stored as glycogen and triglycerides, respectively. Thus, dietary amino acids in excess of the amounts needed for growth and maintenance of protein turnover are preferentially degraded over carbohydrates and lipids in the liver (Campbell, 1991). For fishes with high-protein diets, their dietary carbon is extracted from the carbon chain of amino acids after the removal of the $\alpha$-amino group. Several amino acids, including alanine, are converted to glucose by fish hepatocytes (French et al., 1981) and this process is regulated hormonally in much the same way as it is in mammals. Approximately $40-60 \%$ of the nitrogen intake from food is excreted within $24 \mathrm{~h}$ (Ip et al., 2004c; Lim et al., 2004b). In addition to diet, muscle proteins can act as a source of amino acids, which are catabolized for the production of ATP or carbohydrates, in fasting fishes (Houlihan et al., 1995). Under adverse environmental conditions where ammonia excretion is reduced, some fishes can reduce the rate of ammonia production from amino acid catabolism to slow down the build up of ammonia internally (Ip et al., 2001c, 2004a,b; Lim et al., 2001). During exercise or hypoxia, ammonia can also be produced through the deamination of AMP in the skeletal muscle.
Much of the ammonia produced in fish comes from the $\alpha$-amino group of amino acids that are catabolized. The rate of alanine and glutamine degradation by catfish hepatocytes can account for 50 and $85 \%$, respectively, of the total ammonia excreted by the fish (Campbell et al., 1983). In addition, the rate of glutamate deamination by intact catfish liver mitochondria can account for $160 \%$ of the rate of ammonia excretion (Campbell et al., 1983). For goldfish, the liver is responsible for $50-70 \%$ (van den Thillart and van Raaji, 1995) of ammonia production. Ammonia can be produced either directly in the cytosol of hepatocytes by specific deaminases (histidase, asparaginase, serine dehydratase, and threonine dehydratase; Youngson et al., 1982) or via the combined actions (transdeamination) of cytosolic aminotransferases and mitochondrial GDH (Walton and Cowey, 1977; French et al., 1981), but transdeamination is the primary mechanism for catabolism of amino acids in fish liver (Ballantyne, 2001). Since GDH is localized exclusively in the matrix of fish liver mitochondria, it is within this compartment that ammonia is released through the route of transdeamination which involves the deamination of glutamate (Figure 1). Glutaminase, which releases $\mathrm{NH}_{3}$ from the amide-function of glutamine is also present in the mitochondrial matrix of some fish species. Thus, ammonia released in the matrix of liver mitochondria has to permeate the mitochondrial membranes before excretion.

\section{PASSAGE OF $\mathrm{NH}_{3}$ AND $\mathrm{NH}_{4}^{+}$THROUGH BIOMEMBRANES}

In aqueous solution, ammonia can be present as gaseous $\mathrm{NH}_{3}$ and cationic $\mathrm{NH}_{4}^{+}$, the ratio of which is $\mathrm{pH}$ dependent. The equilibrium reaction between these two components of ammonia can be written as $\mathrm{NH}_{3}+\mathrm{H}_{3} \mathrm{O}^{+} \Leftrightarrow \mathrm{NH}_{4}^{+}+\mathrm{H}_{2} \mathrm{O}$, and the $\mathrm{pK}$ of this $\mathrm{NH}_{3} / \mathrm{NH}_{4}^{+}$reaction is around 9.0-9.5. $\mathrm{NH}_{3}$ reacts avidly with water and is moderately soluble in lipid. Since phospholipids of biological membranes are not very permeable to $\mathrm{NH}_{4}^{+}$, ammonia crosses membranes as $\mathrm{NH}_{3}$ in most cases. $\mathrm{NH}_{3}$ has a high solubility in water and therefore contrasts strongly with lipophilic molecules such as $\mathrm{CO}_{2}$; consequently, the permeability to $\mathrm{NH}_{3}$ of nearly all cell membranes is much less than their permeability to $\mathrm{CO}_{2}$ or $\mathrm{O}_{2}$. Nevertheless, biomembranes are so thin that $\mathrm{NH}_{3}$ can diffuse quite rapidly through nearly all of them, although the $\mathrm{NH}_{3}$ permeability varies greatly and can be very low in some cases (Marcaggi and Coles, 2001). It has been reported that plasma membranes of several mammalian cell types facing the gastric and urinary tracts have relatively low permeability to $\mathrm{NH}_{3}$ (see Marcaggi and Coles, 2001 for a review). On the other hand, ammonia permeation through plasma membranes can also be enhanced by protein channels in certain cell types.

It has been established that the aquaporin (AQP) family generally functions for the selective passage of water or glycerol, but particular aquaporin isoforms can conduct unconventional permeants, including ammonia (Wu and Beitz, 2007). Nakhoul et al. (2001) undertook a study to determine whether expressing AQP1 could affect transport of $\mathrm{NH}_{3}$. Using ion-selective microelectrodes, they conducted experiments on frog oocytes (cells characterized by low $\mathrm{NH}_{3}$ permeability) expressing AQP1, and concluded that the oocyte membrane, although highly permeable to $\mathrm{NH}_{4}^{+}$, had a significant $\mathrm{NH}_{3}$ permeability and that $\mathrm{NH}_{3}$ permeability was enhanced by AQP1. Holm et al. (2005) expressed the mammalian aquaporins AQP8, AQP9, AQP3, and AQP1 in Xenopus oocytes to study the transport of $\mathrm{NH}_{3}$ and $\mathrm{NH}_{4}^{+}$under open-circuit and 




FIGURE 1 |The catabolism of excess amino acids through the process of transdeamination in liver cells releases ammonia and $\alpha$-ketoglutarate ( $\alpha K G$ ) from glutamate (Glu) catalyzed by glutamate dehydrogenase

(GDH) in the mitochondria. To avoid the disruption of the $\mathrm{H}^{+}$gradient set up across the inner mitochondrial membrane by the electron transport system, ammonia produced within the mitochondrial matrix can exit the mitochondrion as $\mathrm{NH}_{4}^{+}$through a putative $\mathrm{NH}_{4}^{+}$transporter (AMT) or a $\mathrm{Na}^{+} / \mathrm{H}^{+}$exchanger (e.g., NHE6) in the liver cells of ammonotelic fishes. Alternately, ammonia can exit through an aquaporin channel (e.g., AQP8) as $\mathrm{NH}_{3^{\prime}}$ accompanied with proton $\left(\mathrm{H}^{+}\right)$transport through an $\mathrm{H}^{+}$-ATPase. Ammonia can also be detoxified through the mitochondrial glutamine synthetase (GS) to glutamine (GIn), which is proton-neutral, before permeating the inner mitochondrial membrane to

voltage-clamped conditions, and concluded that apart from being water channels, they also supported significant fluxes of $\mathrm{NH}_{3}$ and $\mathrm{NH}_{4}^{+}$. By reconstituting purified APQ8 into planar bilayers, Saparov et al. (2007) demonstrated recently through stoichiometric study that it selectively transport $\mathrm{NH}_{3}$, excluding $\mathrm{NH}_{4}^{+}$and $\mathrm{H}^{+}$.

Additionally, members of the Rhesus (Rh) glycoprotein family may play an important role in transmembrane ammonia transport (Bakouh et al., 2006). Among the six clusters of the Rh family, support various anabolic reactions (e.g., purine and pyrimidine syntheses). In ureogenic fishes that possess a functional ornithine-urea cycle, GIn synthesized within the mitochondria can be converted to carbamoyl phosphate (CP) catalyzed by carbamoyl phosphate synthetase III (CPS III) and subsequently to citrulline catalyzed by ornithine transcarbamylase (OTC) in the mitochondrial matrix of liver cells. Citrulline, being proton-neutral, can permeate the inner mitochondrial membrane without disrupting the $\mathrm{H}^{+}$ gradient. Some fishes (e.g., Bostrychus sinensis) possess a high activity of cytosolic GS in the liver (and the muscle), which would facilitate the detoxification of both endogenous and exogenous ammonia to glutamine in the cytosol, with glutamate being supplied from intestinal cells to support increased glutamine synthesis.

RhAG, RhBG, and RhCG are present in most vertebrates and are known to be capable for transporting ammonia and methylammonium (Planelles, 2007). RhCG is expressed in distal nephron sites that are critically important for ammonia secretion, and exhibits increased expression in response to chronic metabolic acidosis. It has been suggested that RhCG contributes to both apical and basolateral membrane ammonia transport in the human kidney (Han et al., 2006). RhCG apparently functions as an $\mathrm{NH}_{3}$ channel, and it 
can be fully active without the contribution of any protein partner (Mouro-Chanteloup et al., 2010). This, however, does not preclude the possibility that, in physiological conditions, RhCG activity could be modulated by other transporters such as the vesiculartype proton pump $\left(\mathrm{H}^{+}\right.$-ATPase $)$and/or the $\mathrm{Cl}^{-} / \mathrm{HCO}_{3}^{-}$exchanger (AE1) expressed in the same epithelial cells in the kidney.

Since $\mathrm{NH}_{4}^{+}$has some ionic properties similar to those of $\mathrm{K}^{+}$, it can compete with $\mathrm{K}^{+}$to be transported through the $\mathrm{K}^{+}$channels (Thomas, 1984; Marcaggi and Coles, 2001). According to Choe et al. (2000), most of the values for $\mathrm{P}_{\mathrm{NH}_{4}} / \mathrm{P}_{\mathrm{K}}$ through $\mathrm{K}^{+}$channels range between 0.1 and 0.3 . However, some $\mathrm{K}^{+}$channels apparently has high specificity for $\mathrm{K}^{+}$, for example, those of the starfish egg, which have a $\mathrm{P}_{\mathrm{NH}_{4}} / \mathrm{P}_{\mathrm{K}}$ value of 0.03 , and the glial cells of bees' retina (see Marcaggi and Coles, 2001 for a review). $\mathrm{NH}_{4}^{+}$can also compete with $\mathrm{K}^{+}$to be transported through $\mathrm{Na}^{+} / \mathrm{K}^{+}$-ATPase and $\mathrm{Na}^{+}: \mathrm{K}^{+}: 2 \mathrm{Cl}^{-}$ cotransporter. Additionally, $\mathrm{NH}_{4}^{+}$transport can also involve the $\mathrm{Na}^{+}$/ $\mathrm{H}^{+}$exchangers (NHE) with $\mathrm{NH}_{4}^{+}$substituting for $\mathrm{H}^{+}$. In some cases, influx of exogenous ammonia as $\mathrm{NH}_{4}^{+}$through various transporters would result in intracellular $\mathrm{NH}_{3}$ cycling leading to a decrease in the intracellular pH (Marcaggi and Coles, 2001).

\section{EFFECTS OF AMMONIA ON THE MITOCHONDRIAL PERMEABILITY TRANSITION AND OXIDATIVE PHOSPHORYLATION Ammonia and the mitochondrial permeability transition}

Brain edema is a critical component of hepatic encephalopathy associated with acute liver failure and such edema appears to be principally due to astrocyte swelling (cytotoxic edema). Ammonia is believed to represent a major factor responsible for astrocyte swelling, although the mechanisms by which ammonia causes such swelling are not completely understood. It has been hypothesized that in hyperammonemic conditions, glutamine generated in astrocytes from ammonia and glutamate in a reaction catalyzed by glutamine synthetase (GS; Norenberg and Martinez-Hernandez, 1979), could exert osmotic effects and contribute to brain swelling (Brusilow and Traystman, 1986). Treatment of hyperammonemic rats with the GS inhibitor, methionine sulfoximine (MSO), significantly reduced the amount of brain edema, and also diminished the extent of astrocyte swelling (Willard-Mack et al., 1996). The integration of astrocyte swelling with ammonia metabolism and glutamine synthesis leads to the glutamine/osmolyte hypothesis explaining the astrocyte swelling and brain edema in hyperammonemia (Zwingmann et al., 2000). However, recent studies revealed a lack of direct correlation between the extent of cell swelling and cellular levels of glutamine (Jayakumar et al., 2006). Although glutamine may not function simply as an osmolyte, it has been proposed that glutamine-mediated oxidative stress and/or mitochondrial permeability transition may be responsible for the astrocyte swelling by ammonia (Jayakumar et al., 2006). While it is not known how oxidative stress and the mitochondrial permeability transition cause astrocyte swelling, Rama Rao and Norenberg (2007) suggested that these events may affect AQP4, which is abundantly expressed in astrocytes (Figure 2). The mitochondrial permeability transition is a $\mathrm{Ca}^{2+}$-dependent, cyclosporine A sensitive process due to the opening of a pore in the inner mitochondrial membrane that leads to a collapse of ionic gradients and results ultimately in mitochondrial dysfunction. Many of the factors that facilitate the induction of the mitochondrial permeability transition are also known to

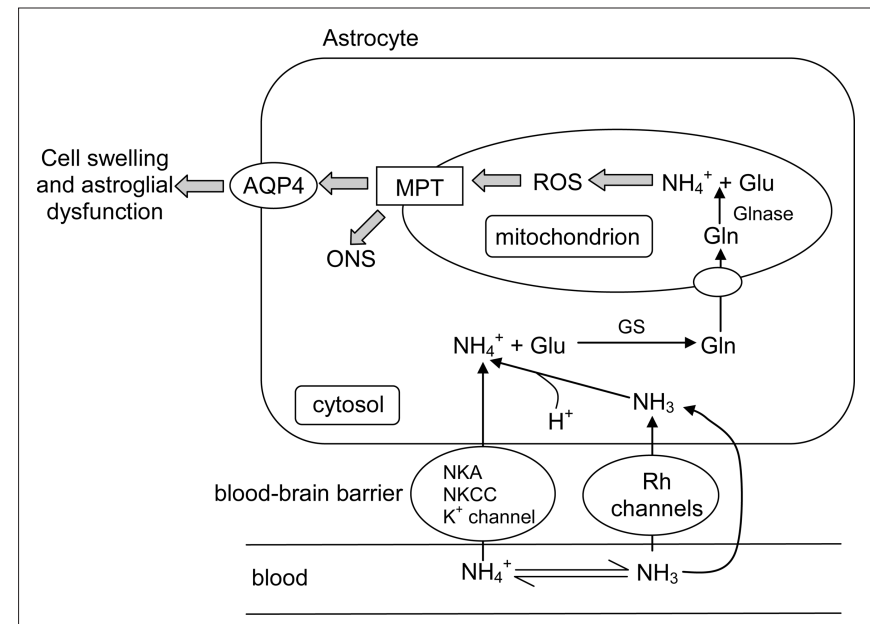

FIGURE 2 |A hypothetical scheme of ammonia-induced astrocyte swelling resulting from (a) the permeation of $\mathrm{NH}_{3}$ and $\mathrm{NH}_{4}^{+}$through the blood-brain barrier with or without the aid of transport proteins (NKA, $\mathrm{Na}^{+} / \mathrm{K}^{+}$-ATPase; NKCC, $\mathrm{Na}^{+}: \mathrm{K}^{+}: 2 \mathrm{Cl}-$-cotransporter; $\mathrm{Rh}$ channels, Rhesus glycoprotein channels) from the blood to the brain, (b) an increase in glutamine (GIn) synthesis from $\mathrm{NH}_{4}^{+}$and glutamate (Glu) catalyzed by glutamine synthetase (GS) in the cytosol, (c) the entry of GIn into the mitochondria, (d) the breakdown of Gln by mitochondrial glutaminase (GInase) and the release of $\mathrm{NH}_{4}^{+}$in the mitochondrial matrix, (e) an increase in the production of reactive oxygen species (ROS), (f) the induction of mitochondrial permeability transition (MPT), (g) the occurrence of oxidative/nitrosative stress (ONS) in the cell, and (h) the activation of aquaporin channels (e.g., AQP4), leading to the influx of water and resulting in swelling and astroglial dysfunction.

be implicated in the mechanism of hepatic encephalopathy; these include free radicals, $\mathrm{Ca}^{2+}$, nitric oxide, alkaline $\mathrm{pH}$, and glutamine. Rama Rao et al. (2003) have shown that treatment of cultured astrocytes with $5 \mathrm{mmol} \mathrm{l}^{-1} \mathrm{NH}_{4} \mathrm{Cl}$ resulted in a dissipation of the mitochondrial membrane potential, which was sensitive to cyclosporine A. Further support for the ammonia induction of the mitochondrial permeability transition was obtained by observing an increase in mitochondrial permeability to 2-deoxyglucose-6-phosphate, and a decrease in calcein fluorescence in astrocytes after ammonia treatment, both of which were also blocked by cyclosporine A. Hence, the mitochondrial permeability transition represents an important component of the pathogenesis of hepatic encephalopathy and other hyperammonemic states. It is the key in cell death in excitotoxicity, in which an over-activation of glutamate receptors causes excessive calcium entry into the cell. Indeed, Reddy et al. (2009) demonstrated that agents that are able to cross the bloodbrain barrier to block the mitochondrial permeability transition significantly reduced ammonia-induced cell swelling.

\section{Exit of $\mathrm{NH}_{3}$ from the mitochondrial matrix can uncouple oxidative phosphorylation}

A non-glycosylated form of the AQP8 protein has been found on the mitochondrial inner membrane of rat liver and several other tissues (Ferri et al., 2003; Calamita et al., 2005; Lee et al., 2005). Surprisingly, in spite of its high water conductance, AQP8 does not appear to have major relevance to the facilitated transport of water across the mitochondrial membranes (Calamita et al., 2006; Gena et al., 
2009). This led Soria et al. (2010) to examine the role of AQP8 in the mitochondrial transport of ammonia by expressing recombinant rat AQP8 in the yeast, Saccharomyces cerevisiae, and determining ammonia transport using formamide (as an ammonia analog) and stopped flow light scattering in isolated yeast mitochondria. It was discovered that the presence of AQP8 increased mitochondrial formamide transport by three-fold (Soria et al., 2010). Subsequently, AQP8-facilitated mitochondrial formamide transport in rat native tissue was confirmed in the liver (a mitochondrial AQP8-expressing tissue) but not in the brain (a mitochondrial AQP8 non-expressing tissue). Furthermore, the AQP8-mediated mitochondrial movement of formamide was markedly higher than that of water. Similar to most members of the AQP family (Pohl, 2004), AQP8 prevents ions from passing the channel, i.e., it allows exclusive transport of the neutral $\mathrm{NH}_{3}$ molecule (Saparov et al., 2007). In physiological concentrations APQ8 may augment the basal $\mathrm{NH}_{3}$ conductivity three- to five-fold (Saparov et al., 2007). Taken together, it can be concluded that under normal circumstances AQP8 facilitates the diffusional exit of $\mathrm{NH}_{3}$ from the matrix of the liver mitochondria through the inner mitochondrial membrane (Figure 3).

Based on the chemiosmotic model for electron transportdependent ATP synthesis, protons are translocated out of the mitochondrial matrix during electron transport across the relatively proton-impermeable inner mitochondrial membrane. This results in a proton $(\mathrm{pH})$ gradient across the membrane such that the matrix is relatively alkaline and the inter-membrane space is relatively acidic (Figure 3). During the re-entry of protons through the ATP synthase complex, the energy provided by the protonmotive force is utilized for ATP synthesis; this is the process of oxidative phosphorylation (Mitchell, 1979). $\mathrm{NH}_{3}$ was one of the first uncouplers of phosphorylation to be used experimentally in the chloroplastal photosynthetic phosphorylation system by Krogmann et al. (1959). Subsequently, Brierly and Stoner (1970) offered experimental support for uncoupling of electron transportdependent phosphorylation by $\mathrm{NH}_{3}$ in mitochondria. When the ionophore valinomycin is added to beef heart mitochondria respiring in $\mathrm{NH}_{4} \mathrm{Cl}$, there is an immediate uncoupling as evidenced by the depletion of $\mathrm{O}_{2}$ in the medium. The postulated mechanism for this is that in the presence of valinomycin, the inner mitochondrial membrane, which is normally impermeable to cations, becomes permeable to $\mathrm{NH}_{4}^{+}$, allowing it to penetrate into the mitochondrial matrix. Subsequently, $\mathrm{NH}_{4}^{+}$turns into $\mathrm{NH}_{3}$ in the matrix due to the alkalinity of this compartment. $\mathrm{NH}_{3}$ then exits the matrix and binds with protons that have been pumped out through electron transport, thereby uncoupling phosphorylation which is accompanied with a marked increase in $\mathrm{O}_{2}$ uptake. An alternate explanation for the uncoupling by $\mathrm{NH}_{4}^{+}$is that it is simply due to the inward transport of $\mathrm{H}^{+}$via protonophores. However, the transient alkalization of the medium following the addition of valinomycin found by Brierly and Stoner (1970) and the absence of osmotic swelling in relation to the accumulation of $\mathrm{NH}_{4}^{+}$in the matrix suggest that the inward transport of protons is not a valid explanation for the uncoupling process.

\section{THE EXIT OF AMMONIA FROM LIVER MITOCHONDRIA OF AMMONOTELIC FISHES - AN ENIGMA}

Many ammonotelic fishes, which excrete more than $50 \%$ of the nitrogenous waste as ammonia, are carnivorous and sustain high rates of hepatic amino acid catabolism (Bever et al., 1981). The liver mitochondria of ammonotelic fishes can sustain glutamate deamination for long periods because of the uncoupling between deamination and transamination. There is little aspartate formation by fish mitochondria from glutamate or glutamine in vitro, even after relative long incubation periods with these substrates (Walton and Cowey, 1977; Campbell et al., 1983). The resulting high rate of mitochondrial amino acid deamination should result in a high

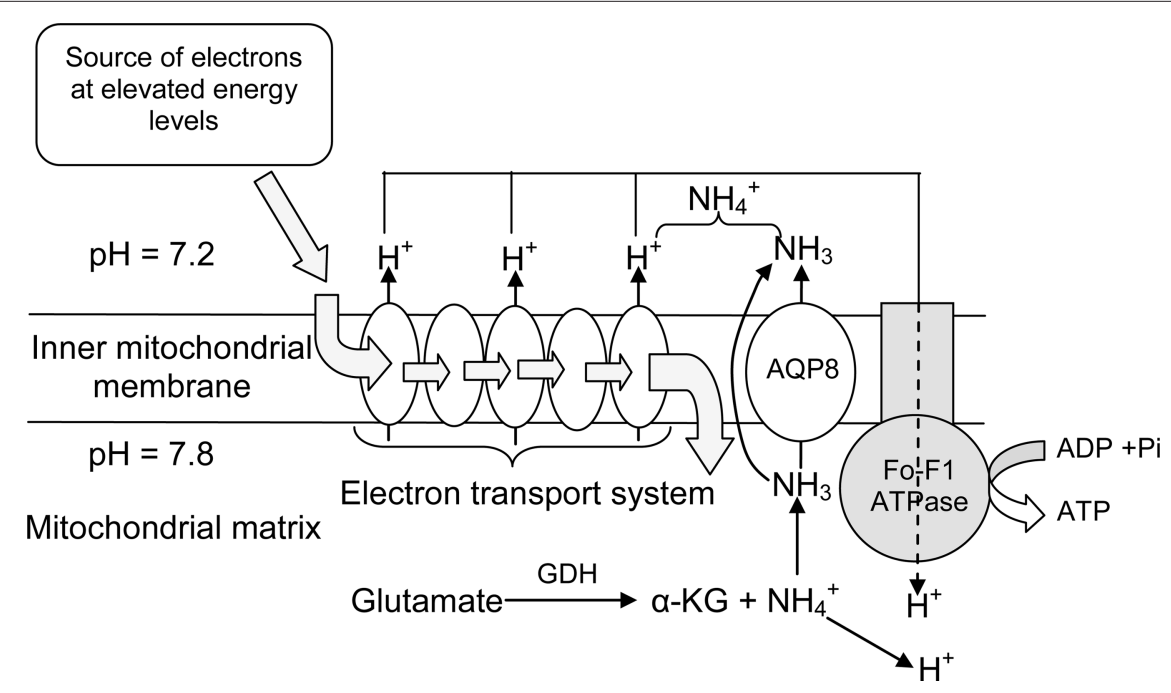

FIGURE 3 |The catabolism of excess amino acids through transdeamination in the liver mitochondrial matrix releases $\alpha$-ketoglutarate ( $\alpha \mathrm{KG}$ ) and $\mathrm{NH}_{4}^{+}$through the deamination of glutamate catalyzed by glutamate dehydrogenase (GDH). Some $\mathrm{NH}_{4}^{+}$would dissociate to $\mathrm{NH}_{3}$ and $\mathrm{H}^{+}$in the matrix which has a more alkaline $\mathrm{pH}$ than the inter-membranous space and the cytosol. The permeation of $\mathrm{NH}_{3}$ through aquaporin channels (e.g., aquaporin 8, APQ8) or the phospholipid bilayer would disrupt the $\mathrm{H}^{+}$gradient set up by the electron transport system (ETS) across the inner mitochondrial membrane and uncouple ETS from oxidative phosphorylation. 
rate of ammonia production and therefore a high rate of ammonia efflux across the inner mitochondrial membrane. A relatively large portion of the ammonia would be present as $\mathrm{NH}_{3}$ in the mitochondrial matrix which has a higher $\mathrm{pH}$ than the inter-membrane region of the mitochondrion and the cytosol. At present, no information is available on the presence of APQ, specifically APQ8 which facilitates the permeation of $\mathrm{NH}_{3}$ in mammalian mitochondria (Soria et al., 2010), in the liver mitochondria of ammonotelic fishes. However, in theory, $\mathrm{NH}_{3}$ efflux from the mitochondrial matrix would result in the uncoupling of oxidative phosphorylation (Figure 3), and hence there is a fundamental issue on the species of ammonia that is transported out of liver mitochondria of ammonotelic fishes. Three mechanisms, which avoid uncoupling oxidative phosphorylation, have been proposed for ammonia efflux from mammalian kidney mitochondria (LaNoue and Schoolwerth, 1979), but there is no evidence for any of these mechanisms to be operative in ammonotelic fishes.

The study by Campbell et al. (1983) is one of the very few that dealt with the enigma on the form of ammonia that exits the inner mitochondrial membrane of a freshwater ammonotelic fish. The basic assumption made by Campbell et al. (1983) was that any increase in ambient $\mathrm{H}^{+}$concentration should cause an increase in the rate of ammonia efflux. However, when the $\mathrm{pH}$ of the medium in which catfish liver mitochondria respiring in the presence of a substrate (glutamine) and ADP was varied between 7.4 and 6.7, a decrease in ammonia efflux occurred with an increase in the proton concentration in the medium. If the ammonia formed in the catfish liver mitochondria via the removal of the amide group of the added glutamine exited the mitochondrial matrix as $\mathrm{NH}_{3}$, an alkalinization would be expected based on the findings of Brierly and Stoner (1970). By contrast, if $\mathrm{NH}_{4}^{+}$was the exiting species, it should result in a slight acidification due to its dissociation into $\mathrm{NH}_{3}$ and $\mathrm{H}^{+}$. Therefore, it would appear that $\mathrm{NH}_{4}^{+}$was the permeating species in catfish liver mitochondria. Furthermore, carbonyl cyanide $p$-(trifluoromethoxy)phenylhydrazone, an uncoupler of oxidative phosphorylation, caused a marked increase in the release of ammonia formed from glutamate in the catfish liver mitochondrial system (Campbell et al., 1983). Since carbonyl cyanide $p$-(trifluoromethoxy)phenylhydrazone is a protonophore and causes a dissipation of the $\mathrm{H}^{+}$gradient across the inner mitochondrial membrane, it was concluded that diffusion-trapping of exiting $\mathrm{NH}_{3}$ by the proton gradient formed by the electron transport system as proposed for kidney mitochondria could not be applied to the catfish liver mitochondria. Rotenone, which directly inhibits the electrogenic $\mathrm{H}^{+}$pump, also had little effect on ammonia efflux from these mitochondria. While the co-transport of glutamate and $\mathrm{H}^{+}$seems an appropriate mechanism for mammalian kidney mitochondria where $\mathrm{NH}_{4}^{+}$formation from glutamine degradation is presumably a means of excreting $\mathrm{H}^{+}$(Flessner et al., 1991), such a mechanism would seem inappropriate for fish liver mitochondria whereby transdeamination, a process that involves the deamination of glutamate, is a major pathway of amino acid catabolism (Campbell et al., 1983; Campbell, 1997).

Overall, the available experimental data suggest that ammonia formed during amino acid catabolism in catfish liver mitochondria exits the mitochondrial matrix as $\mathrm{NH}_{4}^{+}$, and not as $\mathrm{NH}_{3}$ (Figure 1). This is different from carbon dioxide which is also produced in the matrix, but exits the mitochondria mainly as $\mathrm{CO}_{2}$ gas. It is possible that a putative transport protein, which transports $\mathrm{NH}_{4}^{+}$ out of the matrix thereby preventing dissipation of the proton gradient established by the electrogenic $\mathrm{H}^{+}$pump, may be present in liver mitochondria of ammonotelic fish species (Campbell, 1997; Figure 1). Transport of $\mathrm{NH}_{4}^{+}$across the inner mitochondrial membrane may involve NHE, especially NHE6 in higher eukaryotes (Numata et al., 1998; Figure 1). Additionally, the presence of a $\mathrm{H}^{+}$transporter independent of the electron transport chain that acts simultaneously with the translocation of $\mathrm{NH}_{3}$ cannot be ruled out. More importantly, it has been established that ammonia transporters are commonly present in bacteria (Kleiner, 1992; Huang and Peng, 2005). Therefore, assuming a symbiotic origin of mitochondria in eukaryotes, it is logical to deduce their presence in mitochondria. More importantly, these putative mechanisms for $\mathrm{NH}_{4}^{+}$transport through the inner mitochondrial membrane of ammonotelic fishes have been reported to be present in the branchial epithelium of certain amphibious fish species (e.g., the giant mudskipper) and aquatic crustaceans which are capable of excretion of $\mathrm{NH}_{4}^{+}$against an electrochemical gradient (Peng et al., 1998; Randall et al., 1999, 2004; Wilson et al., 2000; Ip et al., 2004d; Weihrauch et al., 2009). Therefore, an examination of the presence of transporters that would facilitate the exit of $\mathrm{NH}_{4}^{+}$from the matrix of, but avoid uncoupling oxidative phosphorylation in, the liver mitochondria of ammonotelic fishes is warranted.

\section{EXCRETION OF AMMONIA IN AMMONOTELIC FISHES}

The gills are the primary site of ammonia excretion in fish (Wilkie, 1997, 2002; Weihrauch et al., 2009), because they have large surface area, perfusion by $100 \%$ of cardiac output, large ventilation rates, small diffusion distances, and contact with a voluminous mucosal medium (Evans et al., 2005). Although gill tissues exert an extremely high metabolic rate, accounting for almost $10 \%$ of the entire oxygen demand of teleosts for osmoregulatory purposes, the overall metabolic expenditures for the release of ammonia appear to be minimal (Evans et al., 2005). For most ammonotelic fishes, the majority of ammonia is excreted across the branchial epithelium as $\mathrm{NH}_{3}$, down a favorable blood-to-water diffusion gradient (Wilkie, 1997, 2002; Evans et al., 2005). In freshwater fishes (Figure 4), excreted $\mathrm{NH}_{3}$ can be trapped via $\mathrm{H}^{+}$secretion or $\mathrm{CO}_{2}$ excretion into the unstirred layer of water on the apical surface of the gills (Avella and Bornancin, 1989). $\mathrm{H}^{+}$secretion can be achieved through an apical vesicular type of $\mathrm{H}^{+}$-ATPase (see Lin and Randall, 1995 for a review), and there is an apparent lack of $\mathrm{Na}^{+} / \mathrm{H}^{+}\left(\mathrm{NH}_{4}^{+}\right)$exchange via NHE in gills of freshwater fishes (Evans et al., 2005). For marine fishes (Figure 5), despite the presence of NHE, which facilitates $\mathrm{Na}^{+}$ absorption, little to no ammonia excretion occurs through $\mathrm{Na}^{+}$/ $\mathrm{NH}_{4}^{+}$exchange (Wilkie, 2002) because of the presence of favorable $\mathrm{NH}_{3}$ and $\mathrm{NH}_{4}^{+}$diffusion gradients. Unlike freshwater fishes, marine fishes have leaky tight junctions between mitochondrion-rich cells, which increase cation permeability for $\mathrm{Na}^{+}$secretion. Therefore, a significant portion of ammonia can be excreted through $\mathrm{NH}_{4}^{+}$diffusion through the paracellular route in seawater fishes (Goldstein et al., 1982).

Traditionally, it has been accepted that $\mathrm{NH}_{3}$ diffusion occurs across the phospholipid bilayer of the branchial epithelium, but research in the past decade reveals that permeation of ammonia 


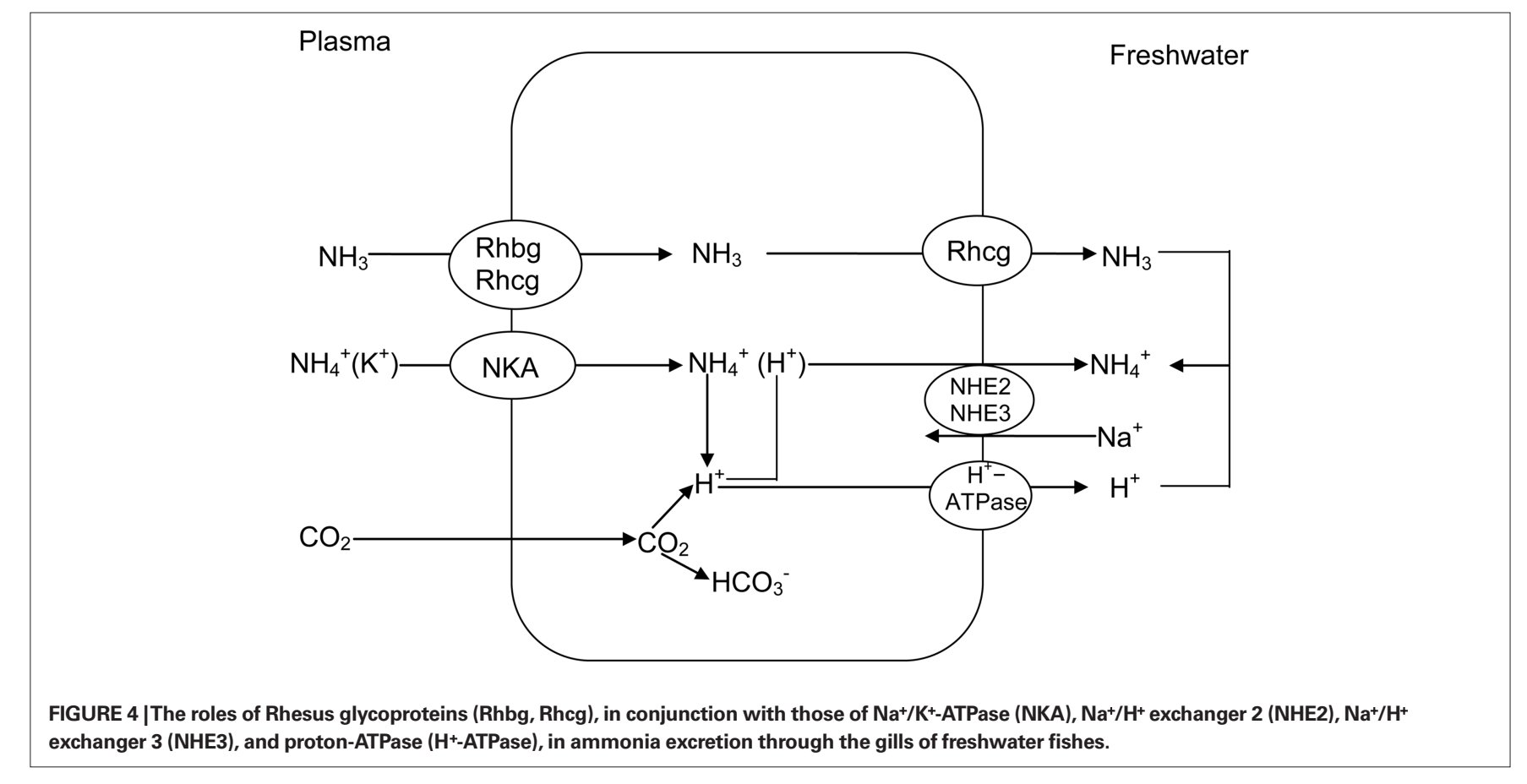
exchanger 3 (NHE3), and proton-ATPase ( $\mathrm{H}^{+}-$ATPase), in ammonia excretion through the gills of freshwater fishes.

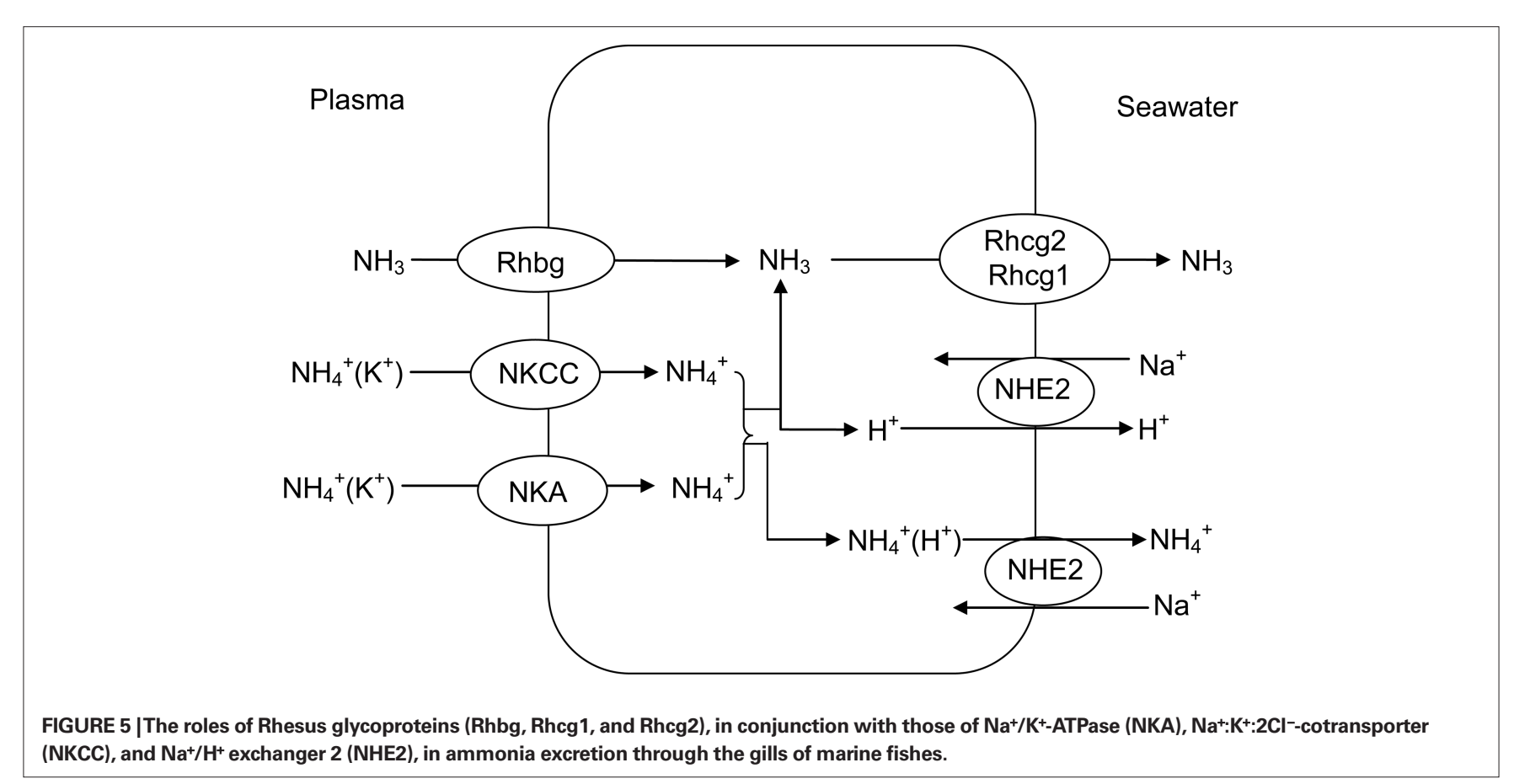

across fish gills can involve transporters (Huang and Peng, 2005; Weihrauch et al., 2009; Wright and Wood, 2009). Within the ammonoteles, $\mathrm{Rh}$ glycoproteins are beginning to emerge as vital ammonia conduits (Figures 4 and 5). Nawata et al. (2007) confirmed the expression of seven Rh genes, with the suggestive role in ammonia excretion, in the gills of the rainbow trout. In a study of Rh gene expression in early life history stages of rainbow trout, Hung et al. (2008) discovered substantial expression of Rhbg, $R h c g 1$, and $R h c g 2$ mRNAs in rainbow trout whole embryo extracts that exhibited temporal dynamics consistent with developmental changes in nitrogen excretion patterns. Nakada et al. (2007a) also confirmed the expression of Rh gene on the surface of the yolk sac of zebrafish. Using scanning ion-specific electrode technique and knockdown methods, Shih et al. (2008) obtained results which indicate that the proton-ATPase-rich cells of the zebrafish yolk sac skin were involved in ammonia and acid excretion. Furthermore, Nakada et al. (2007b) identified the Rh glycoprotein homologs, fRhag, fRhbg, fRhcg1, and fRhcg2, of the pufferfish, Takifugu 
rubripes. All four glycoproteins were localized in the gill; they lined the pillar cells, pavement cells, and the mitochondrion-rich cells. Heterologous expression of these glycoproteins in Xenopus oocytes showed that they mediated methylammonium (an analog of ammonium) transport. Results obtained by Nakada et al. (2007b) suggest that pufferfish Rh glycoproteins are involved in ammonia excretion from the gill, and challenge the classic view that ammonia excretion in the fish gill occurs by passive diffusion across the phospholipid bilayer. Nawata et al. (2010) studied the involvement of Rh glycoproteins in ammonia transport through the gills of the rainbow trout, using oocyte expression and scanning ion-specific electrode technique. Their results are consistent with the current model in which ammonia passes through the $\mathrm{Rh}$ channels as $\mathrm{NH}_{3}$ (Mouro-Chanteloup et al., 2010).

Specifically, Rhcg appears to be localized in apical membranes and Rhbg in basolateral membranes in the branchial epithelium. Their gene expression is up-regulated during exposure to high environmental ammonia or internal ammonia infusion, and may be sensitive to synergistic stimulation by ammonia and cortisol. Rhcg in particular appears to be coupled to $\mathrm{H}^{+}$excretion and $\mathrm{Na}^{+}$uptake mechanisms. Wright and Wood (2009) proposed a new model for ammonia excretion in freshwater fish and its variable linkage to $\mathrm{Na}^{+}$uptake and acid excretion. In their model, Rhcg facilitates $\mathrm{NH}_{3}$ flux out of the erythrocyte, Rhbg moves it across the basolateral membrane of the branchial ionocyte, and an apical " $\mathrm{Na}^{+} / \mathrm{NH}_{4}^{+}$ exchange complex" consisting of several membrane transporters (Rhcg, vesicular-type $\mathrm{H}^{+}$-ATPase, $\mathrm{Na}^{+} / \mathrm{H}^{+}$exchanger NHE-2 and/ or NHE-3, $\mathrm{Na}^{+}$channel) working together as a metabolon provides an acid trapping mechanism for apical excretion. Intracellular carbonic anhydrase and basolateral $\mathrm{Na}^{+} / \mathrm{HCO}_{3}^{-}$cotransporter and $\mathrm{Na}^{+} / \mathrm{K}^{+}$-ATPase play indirect roles in ammonia transport. These mechanisms are normally superimposed on a substantial outward movement of $\mathrm{NH}_{3}$ by simple diffusion, which is probably dependent on acid trapping in boundary layer water by $\mathrm{H}^{+}$ions created by the catalyzed or non-catalyzed hydration of expired metabolic $\mathrm{CO}_{2}$ (Wright and Wood, 2009).

Recently, Braun et al. (2009) used the injection of antisense oligonucleotide morpholinos to elicit selective gene knockdown of ammonia transporters (Rhag, Rhbg, and Rhcg1) to assess the relative importance of each transporter to nitrogen excretion in developing zebrafish. Knockdown of each of the Rh protein resulted in a 50\% reduction in ammonia excretion. Contrary to what has been hypothesized previously for adult fish, each of the $\mathrm{Rh}$ proteins appeared to have a similar effect on total ammonia excretion, and thus all are required to facilitate normal ammonia excretion in the zebrafish larva. At the point of hatching, ammonia excretion rapidly increased and appeared to be triggered by a large increase in the mRNA expression of Rhag, Rhbg, and Rhcg1. Unlike the situation in the adult pufferfish, the various transporters are not specifically localized on the gills of the developing zebrafish (Nakada et al., 2007a), but each protein has a unique expression pattern along the skin, gills, and yolk sac. This disparate pattern of expression would appear to preclude interaction between the $\mathrm{Rh}$ proteins in zebrafish embryos. However, this may be a developmental feature of the delayed maturation of the gills, because as the embryos matured, expression of the transporters in and around the gills increased.

\section{IMPEDIMENT OF AMMONIA EXCRETION, AMMONIA-LOADING, AND MECHANISMS OF AMMONIA TOXICITY IN FISH ENVIRONMENTAL CONDITIONS THAT IMPEDE AMMONIA EXCRETION OR LEAD TO AN INFLUX OF AMMONIA}

While excretion of ammonia is not a problem at low environmental $\mathrm{pH}$, it is a major problem for fish exposed to high $\mathrm{pH}$. This is because at high environmental $\mathrm{pH}$, worst still with high buffering capacity (Weihrauch et al., 2009), the gradient for $\mathrm{NH}_{3}$ diffusion is reduced and this may lead to a build up of ammonia inside the fish (Wilkie and Wood, 1996). Death can occur when the rise in plasma ammonia level is too rapid and/or toxic levels of ammonia are reached (Wilkie et al., 1993).

Air-breathing is one of several adaptive responses utilized by fishes dwelling in habitats where $\mathrm{O}_{2}$ supplies may be severely depleted (Graham, 1997). While most air-breathing fishes remain aquatic, some evolved to emerge from water, make excursion onto land, or even burrow into mud when the external media dry up. When a fish is out of water, it is confronted with problems of endogenous ammonia excretion because there is a lack of water to flush the branchial and cutaneous surfaces. So, amphibious air-breathing fishes must have adaptation to ameliorate ammonia toxicity during long term emersion (see Ip et al., 2001c, 2004a; Chew et al., 2006b for reviews).

Some air-breathing fishes can be trapped in puddles of water occasionally, or in crevices for many days; continual excretion of endogenous ammonia into a small volume of external media can lead to high external ammonia concentrations. Furthermore, water evaporation at the high temperatures of the tropics can concentrate environmental ammonia to high levels. In addition, fishes can be exposed to high concentrations of environmental ammonia under several conditions. Some tropical fishes may have unique behaviors; for example, mudskippers build burrows in the mud in estuaries and stay therein during high tides. During the breeding season, the male fish stays inside the burrow for 1-2 months to take care of the developing embryos and fry. Since the burrow water is not well flushed, the ammonia concentrations can be high, and mudskippers have to deal with the toxicity of environmental ammonia in the burrow. Some fishes live in rice fields, where agricultural fertilization can lead to high concentrations of environmental ammonia. In the presence of high concentrations of environmental ammonia, fishes are confronted simultaneously with retention of endogenous ammonia and uptake of exogenous ammonia, and they have special adaptations to deal with ammonia toxicity (see Ip et al., 2004b; Chew et al., 2006b, for reviews).

\section{DELETERIOUS EFFECTS OF ENDOGENOUS AMMONIA}

Since the $\mathrm{pH}$ of fish blood and intracellular fluid is approximately 1-2 units below the $\mathrm{p} K$ of ammonia, more than $95 \%$ of the ammonia exists as $\mathrm{NH}_{4}^{+}$in the cytosol and plasma of fish. Once in the plasma, ammonia will be circulated to other part of the fish body; were it allowed to accumulate many deleterious effects will develop because ammonia is toxic and it affects various cellular processes (Ip et al., 2001b; Randall and Tsui, 2002). Ammonia stimulates glycolysis in fish by activating phosphofructokinase I in the cytosol. It also interferes with energy metabolism through impairment of the tricarboxylic acid cycle in the mitochondria (Arillo et al., 1981). Ammonia affects the ionic balance in fish at both cellular and at 
the organismal levels, reducing $\mathrm{Na}^{+}$influx and $\mathrm{K}^{+}$loss through substitution of $\mathrm{NH}_{4}^{+}$for $\mathrm{K}^{+}$in $\mathrm{Na}^{+} / \mathrm{K}^{+}$-ATPase and/or $\mathrm{Na}^{+}: \mathrm{K}^{+}: 2 \mathrm{Cl}^{-}$ co-transport (see Wilkie, 2002 for a review). In addition, $\mathrm{NH}_{4}^{+}$can substitute for $\mathrm{H}^{+}$in $\mathrm{Na}^{+} / \mathrm{H}^{+}$exchange in marine fishes (probably NHE2 and/or NHE3, Randall et al., 1999).

The most acute effects of ammonia are probably related to the ability of $\mathrm{NH}_{4}^{+}$to substitute for $\mathrm{K}^{+}$in ion transporters (Binstock and Lecar, 1969) and disrupt electrochemical gradients in central nervous systems (Cooper and Plum, 1987). Because fishes have less advanced central nervous systems than higher vertebrates, this may explain why fishes are more tolerant of ammonia than mammals (Evans et al., 2005). Several theories (glutamatergic dysfunction, glutamine accumulation leading to astrocyte swelling, activation of $N$-methyl-D-aspartate-type (NMDA) glutamate receptors) have been proposed to address the mechanisms of acute ammonia toxicity in mammalian brains (Brusilow, 2002; Felipo and Butterworth, 2002; Rose, 2002), but they have yet to be confirmed in fish.

The mechanisms of ammonia toxicity in the brains of some fishes with high ammonia tolerance apparently differ from those in mammalian brains (Opsanus beta, Veauvy et al., 2005; Periophthalmodon schlosseriand Boleophthalmus boddarti, Ip et al., 2005a; Clarias gariepinus, Wee et al., 2007; Monopterus albus, Tng et al., 2009). MSO, at a dosage $\left(100 \mu \mathrm{g} \mathrm{g}^{-1}\right.$ fish) protective for rats, does not reduce the mortality of two species of mudskippers, P. schlosseri and B. boddarti, injected with a lethal dose of $\mathrm{CH}_{3} \mathrm{COONH}_{4}$, indicating that increased glutamine synthesis and accumulation in the brain is not the major cause of death (Ip et al., 2005a). The prior administration of MSO (100 $\mathrm{g} \mathrm{g} \mathrm{g}^{-1}$ fish) reduces the mortality of the African catfish, C. gariepinus, injected with a lethal dose of $\mathrm{CH}_{3} \mathrm{COONH}_{4}$ from 100 to $80 \%$ and prolongs the time of death from 27 to $48 \mathrm{~min}$ (Wee et al., 2007). However, the protective effect of MSO may be unrelated to the inhibition of GS and prevention of glutamine accumulation. Wee et al. (2007) demonstrated that MSO also suppressed the rate of ammonia build up in the brain of the African catfish, C. gariepinus, probably through inhibiting activities of GDH and alanine aminotransferase therein, as it does in vitro when MSO was added to the enzyme assay mixture. The demonstration of unchanged maximal activities of these two enzymes extracted from the brain of $C$. gariepinus with or without MSO treatment, as reported by Wee et al. (2007), did not necessarily indicate the absence of changes in activities in vivo as suggested by Sanderson et al. (2010), since enzymes rarely operate at maximal activities and saturating substrate levels in situ. Sanderson et al. (2010) reported a lack of changes in ammonia and glutamate levels accompanied with increases in contents of several amino acids in the brain of rainbow trout pre-injected with MSO followed with exposure to environmental ammonia (0.6 or $1.0 \mathrm{mmoll}^{-1}$ ) as compared with the control without MSO treatment. They (Sanderson et al., 2010) concluded that rainbow trout possessed a relatively large reserve capacity for ammonia detoxification and for preventing glutamate accumulation during hyperammonemic conditions. However, these observations could also be explained by the possible suppression of GDH activities by MSO in vivo leading to decreases in catabolism of certain amino acids and consequently the accumulation of these amino acids and a reduction in ammonia production, although it is uncertain at present whether MSO would affect GDH activity from the rainbow trout, as in the case of the African catfish. As for the swamp eel, M. albus, it can survive a sublethal dose (10 $\mu \mathrm{mol} \mathrm{g}{ }^{-1}$ fish) of intraperitoneal injection with $\mathrm{CH}_{3} \mathrm{COONH}_{4}$ by having high ammonia tolerance at the cellular level, detoxifying ammonia to glutamine in and outside the brain, and reducing the production of endogenous ammonia (Tng et al., 2009). Those fish that succumbed to a lethal dose ( $16 \mu \mathrm{mol} \mathrm{g} \mathrm{g}^{-1}$ fish) of $\mathrm{CH}_{3} \mathrm{COONH}_{4}$ has an extraordinary high content of ammonia in the brain, and therefore, unlike mammals, increased glutamine synthesis and accumulation might not be the major cause of death. Although MSO exhibits a partial protective effect against acute ammonia toxicity in $M$. albus, it is unrelated to the prevention of glutamine accumulation (Tng et al., 2009). Instead, MSO apparently reduced the rate of ammonia build up in the brain of M. albus through its effect on GDH. Taken together, these results indirectly indicate that fish brains can suppress ammonia production.

In mammals, acute ammonia intoxication is mediated by activation of NMDA receptors (Hermenegildo et al., 1996; Kosenko et al., 1999); and, excessive activation of these receptors is neurotoxic, leading to oxidative stress, neuronal degeneration and death (Miñana et al., 1996). However, the brain of B. boddarti also experiences ammonia-induced oxidative stress (Ching et al., 2009), although ammonia apparently does not induce excessive activation of NMDA receptor in the brain of this fish (Ip et al., 2005a). Exposure of B. boddarti to $8 \mathrm{mmol} \mathrm{l}^{-1} \mathrm{NH}_{4} \mathrm{Cl}$ for 12 or $24 \mathrm{~h}$ leads to the accumulation of carbonyl proteins, elevation in oxidized glutathione content and oxidized:reduced glutathione ratio, decreases in activities of glutathione reductase and catalase, and an increase in the activity of superoxide dismutase (Ching et al., 2009). The capacity to increase glutathione synthesis and reduced glutathione content could alleviate severe ammonia-induced oxidative and nitrosative stress in the brain. Furthermore, the ability to decrease the protein abundance of p38 and phosphorylated p53 might prevent cell swelling, contributing in part to the high ammonia tolerance in the brain of B. boddarti. More importantly, ammonia can also induce oxidative stress in the gills of $B$. boddarti, an organ that lacks NMDA receptors (Ching et al., 2009). Hence, there could be multiple routes through which ammonia induces oxidative stress in brain or non-brain tissues. It is possible that ammonia directly affected the intracellular $\mathrm{NO}$ and/or $\mathrm{Ca}^{2+}$ concentrations, the increase of which can lead to increased production of free radicals (HernándezFonseca et al., 2008), in the gills and brain of B. boddarti.

\section{DELETERIOUS EFFECTS OF ENVIRONMENTAL AMMONIA}

Unlike terrestrial tetrapods, fish respire mainly through gills, which would be directly exposed to exogenous ammonia during environmental ammonia exposure. Ammonia must permeate through the branchial and cutaneous epithelia before being transported through the blood to the brain and other organs. As an active respiratory and osmoregulatory organ, fish gills have a high capacity to produce reactive oxygen species, and Ching et al. (2009) indeed reported that exposure to environmental ammonia resulted in oxidative stress in the gills of $B$. boddarti. In addition, environmental ammonia has deleterious effects on branchial ion transport not associated with the accumulation of endogenous ammonia. These effects are not applicable to fish simply exposed to terrestrial conditions or to fish injected/infused with exogenous ammonia. Acute exposure to environmental ammonia results in the inhibition of $\mathrm{Na}^{+}$influx in the temperate rainbow trout O. mykiss (Avella and 
Bornancin, 1989) and the goldfish Carassius auratus (Maetz, 1973). In C. auratus, the deleterious effect is specific to $\mathrm{Na}^{+}$uptake and not general to the epithelium or all ion uptake mechanisms. In contrast, no deleterious effect of ammonia exposure (up to $28.2 \mu \mathrm{mol} \mathrm{l^{-1 }}$ $\mathrm{NH}_{3}-\mathrm{N}$ or $5.2 \mathrm{mmol} \mathrm{l}^{-1}$ total ammonia) is seen on $\mathrm{Na}^{+}$uptake in juvenile rainbow trout, but $\mathrm{Na}^{+}$efflux is stimulated by ammonia levels greater than $6.4 \mu \mathrm{moll}^{-1} \mathrm{NH}_{3}-\mathrm{N}\left(1.2 \mathrm{mmoll}^{-1}\right.$ total ammonia) (Twitchen and Eddy, 1994). This increase in efflux is likely through an increased $\mathrm{Na}^{+}$permeability of the gills (Gonzalez and McDonald, 1994), mediated through a modulation of the paracellular pathway (Madara, 1998). In addition, exposure to environmental ammonia predisposes the gills to histopathological changes that may disrupt ion transport (Daoust and Ferguson, 1984). Disruption of epithelial integrity has adverse consequences for ion transport and other cellular processes, and the proliferation of branchial mucous cells induced by environmental ammonia increases diffusion distances across the gill (Ferguson et al., 1992).

\section{PASSAGE OF PROTON-NEUTRAL NITROGENOUS COMPOUNDS ACROSS MITOCHONDRIAL MEMBRANES - COOPERATION BETWEEN CYTOSOLIC AND MITOCHONDRIAL ENZYMES TO DETOXIFY AMMONIA \\ DETOXIFICATION OF AMMONIA TO GLUTAMINE}

In ureogenic and ureotelic animals, including humans, the main mechanism for keeping the internal concentration of ammonia low is by detoxifying ammonia to urea which is eliminated in urine. Urea synthesis occurs primarily in the liver through the ornithineurea cycle (OUC). In other tissues, including the brain, that do not possess a functional OUC, ammonia is mainly detoxified to glutamine, which is then released to the blood stream and may serve as a non-toxic carrier of ammonia from different tissues to the liver. Glutamine formation plays a major role in detoxifying exogenous and endogenous ammonia in non-ureogenic fishes, especially in the brain, during exposure to exogenous/environmental ammonia (Arillo et al., 1981; Dabrowska and Wlasow, 1986; Mommsen and Walsh, 1992; Peng et al., 1998; Lim et al., 2004a; Ip et al., 2005a; Veauvy et al., 2005; Wee et al., 2007; Wright et al., 2007; Tng et al., 2009; Sanderson et al., 2010) or after feeding (Wicks and Randall, 2002; Lim et al., 2004b). In certain fish species, like the swamp eel, M. albus (Tok et al., 2009), and the Amazonian freshwater stingray, Potamotrygon motoro (Ip et al., 2009), glutamine synthesized from endogenous ammonia can act as an important osmolyte for cell volume regulation during acclimation to high salinity. As for ureogenic and ureosmotic fishes, glutamine can act as a substrate for the synthesis of urea which is essential for osmoregulation in a hyperosmotic environment.

Glutamine is produced from glutamate and $\mathrm{NH}_{4}^{+}$, the reaction catalyzed by GS, and multiple GS genes have been reported for the rainbow trout (Murray et al., 2003; Walsh et al., 2003; Wright et al., 2007). Glutamate may in turn be produced from $\alpha$-ketoglutarate $(\alpha-\mathrm{KG})$ and $\mathrm{NH}_{4}^{+}$, catalyzed by the aminating activity of $\mathrm{GDH}$, in the mitochondria of cells that are not geared toward the catabolism of amino acids through transdeamination. It can also be produced from $\alpha-K G$ and other amino acids catalyzed by various transaminases in the mitochondria and/or the cytosol. It has been reported that the brain of the rainbow trout exhibits higher GS activity than GDH activity (Wright et al., 2007), but it is important to take note that the GS activity was determined by the transferase assay, and the transferase activity is known to be $\sim 20$-fold greater than the biosynthetic activity. Whether the synthesis of glutamine begins with glutamate or $\alpha-K G$ is determined by the compartmentalization of GS within the cell (Figures 1 and 2). Webb and Brown Jr. (1976, 1980) determined the distribution of GS in tissues of ureosmotic and non-ureosmotic fishes, and reported the presence of high levels of GS in the cytosolic fraction of brain tissues of both group of fishes (Figure 2). Interestingly, in mammalian liver, GS is also present in the cytosolic compartment of perivenule hepatocytes (Wu, 1963) and appears to function in these cells as "fail-safe" mechanism for ammonia detoxification when the capacity for urea synthesis is exceeded. However, for ureosmotic fishes, the liver tissues also contained high levels of GS activity in the mitochondria (Figure 1). Furthermore, results obtained by Webb and Brown Jr. (1976, 1980) showed that certain non-ureosmotic fishes possessed relatively low activities of cytosolic GS in the livers. GS is also detected from the mitochondria of elasmobranch kidney, which may function as part of a substrate cycle for ammonia excretion during acidosis (King and Goldstein, 1983).

A major portion of ammonia is produced in the liver, and since $\mathrm{NH}_{3}$ is an uncoupler of oxidative phosphorylation and exerts its deleterious effect during exit from the matrix of the mitochondrion, it is logical for it to be detoxified to a less toxic (or non-toxic) product before crossing the inner membrane of liver mitochondria. For the detoxification of endogenous ammonia, which is produced through transdeamination, to glutamine (or finally to urea in ureogenic fishes), it is essential for GS to be located in the mitochondrial matrix (Figure 1). Under such a situation, glutamate serves the dual functions of providing $\mathrm{NH}_{3}$ and acting as a direct substrate for glutamine formation inside the mitochondrion. Glutamine formed in the mitochondrial matrix can exit to the cytosol where it serves as a precursor for various biosynthetic pathways (Figure 1). Glutamine shows no protonation of its $\mathrm{R}$ chain over a wide range of $\mathrm{pHs}$ and is therefore protonneutral (Campbell, 1991, 1997). The physiological consequence of this is that $\mathrm{NH}_{3}$ in the mitochondrial matrix, whether arising by deamination of glutamate via GDH or the direct entry of $\mathrm{NH}_{3}$ or $\mathrm{NH}_{4}^{+}$, exits to the cytosol as a proton-neutral amide-function of glutamine. Through this, the problem of uncoupling oxidative phosphorylation by $\mathrm{NH}_{3}$ is circumvented.

Ammonia circulating in the plasma asserts its toxic effects on the brain, and fish brains possess high levels of GS activities to protect them against ammonia toxicity (Peng et al., 1998; Ip et al., 2005a; Wright et al., 2007). If GS were to be located in the mitochondria, it would render the detoxification of exogenous ammonia inefficient as $\mathrm{NH}_{3}$ would have to permeate through both the plasma and mitochondrial membranes to be processed by the mitochondrial GS. In fact, $\mathrm{NH}_{3}$ would bind with $\mathrm{H}^{+}$after entering the cytosol to form $\mathrm{NH}_{4}^{+}$, and ammonia would begin to exert its toxic effects. Hence, GS in brains of fishes are located in the cytosol (Figure 2); this specific location facilitates the detoxification of ammonia circulated in the blood, and prevents the brain from ammonia intoxication. In the case of marine elasmobranchs which depend on urea synthesized through carbamoyl phosphate synthetase III (CPS III) in the liver for osmoregulation, two isoforms of GS exist separately in the brain and the liver, which are localized in the 
cytosol and the mitochondria, respectively (Smith Jr. et al., 1983). In many tropical fishes, high levels of cerebral GS activities correlate well with their high environmental ammonia tolerance. As a result, the brain is often the organ undergoing the largest increases in glutamine content in fish exposed to ammonia. In mammal, it has been established that glutamine accumulation would lead to astrocyte swelling and brain edema. Recent studies have shown that glutamine can directly exert toxic effects on cultured astrocytes by increasing reactive oxygen species production and by inducing the mitochondrial permeability transition (Rama Rao et al., 2003; Jayakumar et al., 2004; Figure 2). How fish brains, especially those with high brain ammonia tolerance and accumulate high levels of glutamine, avoid these supposedly deleterious effects is uncertain at present. Since inhibiting mitochondrial glutamine hydrolysis in astrocytes of mammals mitigates many of the toxic effects of ammonia, it has been proposed that mitochondrial glutamine metabolism is involved in the mechanism of ammonia neurotoxicity (Pichili et al., 2007). Treatment of cultured astrocytes with L-histidine, an inhibitor of mitochondrial glutamine transport, completely blocked or significantly attenuated ammonia-induced reactive oxygen species production, cell swelling, mitochondrial permeability transition, and loss of ATP, indicating the intricate relationships between mitochondrial glutamine transport and intra-mitochondrial glutaminase in the mechanism of ammonia neurotoxicity (Pichili et al., 2007; Figure 2). Hence, it would be essential to examine the regulation of glutamine translocation across the inner membrane and the degradation of glutamine by glutaminase in the matrix of the brain mitochondria of fish species that can accumulate high levels of glutamine in the brain without any apparent deleterious effect.

He et al. (2010) reported recently that muscle GS is involved in glutamine production in mouse during fasting or undergoing extra-hepatic ammonia detoxification, although it has been established for almost a decade that ammonia can be detoxified to glutamine in non-cerebral tissues, including muscle, of some fish species. Certain air-breathing fishes, for instance, sleepers (the marble goby, O. marmoratus, and four-eyed sleeper, B. sinensis) belonging to the family Eleotridae and the swamp eel, M. albus, belonging to family Synbranchidae, can detoxify endogenous ammonia to glutamine in their livers and muscles during aerial exposure (Jow et al., 1999; Ip et al., 2001a; Tay et al., 2003) and ammonia-loading (Anderson et al., 2002; Ip et al., 2004f; Chew et al., 2005a). In B. sinensis, virtually all the GS activity in the liver is located in the cytosol, and it can be up-regulated through increased expression of the gene during ammonia exposure (Anderson et al., 2002). It is unlikely that the increased glutamine synthesis in the cytosol under such conditions is supported by an increase in the production of glutamate through the GDH amination reaction in the mitochondrial matrix of liver cells since the GDH would be involved in the transdeamination reaction (Figure 1). Glutamine synthesized is stored within the body, and it can be used for other anabolic processes (e.g., syntheses of purine, pyrimidine and mucopolysaccharides) when the environmental conditions become more favorable. The aquatic-breathing Gulf toadfish, $O$. beta, is another unique example; it detoxifies endogenous ammonia to glutamine to suppress ammonia excretion during confinement stress (Walsh and Milligan, 1995).
The fish intestine is a complex multifunctional organ; besides digestion and absorption, it is crucial for water and electrolyte balance, endocrine regulation of digestion and metabolism, and immunity. For juvenile marble goby O. marmorata kept in freshwater, it is noteworthy that the activity of GS from the intestine is six-fold higher than that from the liver (Chew et al., 2009). Similarly, intestinal GS activity is $\sim 5.7$-fold higher than hepatic GS activity in the four-eyed sleeper, B. sinensis (Anderson et al., 2002). Mommsen et al. (2003) also reported high levels of GS activity in the gastrointestinal tract of the tilapia, O. mossambicus, and hypothesized that GS was concentrated toward the posterior section of the intestine for the efficient trapping of ammonia generated upstream in the intestinal tract as a by-product of digestion or through microbial processes. However, upon feeding, the glutamine content in the intestine of juvenile O. marmorata does not increase throughout the 24 -h postprandial period in spite of a significant increase in the glutamate content therein and an increase in the GS activity at hour 12 (Tng et al., 2008). Instead, intestinal GDH activities, in both amination and deamination directions, increase significantly in juvenile O. marmorata $12 \mathrm{~h}$ after feeding. Increased production of glutamate after feeding can be an important adaptation to avoid or reduce postprandial ammonia toxicity (Tng et al., 2008). Subsequently, Chew et al. (2010) reported that exposure to seawater for 14 days also led to a significant increase in GDH activities, in the amination directions, and in GDH protein abundance from the intestine of juvenile O. marmorata. Their results (Chew et al., 2010) suggest that excess glutamate formed in the intestine could be transported to the liver and muscle to facilitate increased amino acid synthesis for the purpose of cell volume regulation (Chew et al., 2009). Furthermore, Peh et al. (2009) reported recently that the intestinal GDH was involved in ammonia detoxification in $B$. sinensis exposed to environmental ammonia in seawater. It was essential for the intestine to supply glutamate through increased GDH amination activity to the liver (and other organs) to support increased glutamine synthesis because liver is the main site of glutamate catabolism (Campbell, 1991). Excess free amino acids that are not used for protein synthesis and other essential functions are catabolized to ammonia and the corresponding $\alpha$-keto acids through transdeamination in the liver (Campbell, 1991). Since transdeamination involves the degradation of glutamate, the hepatic GDH would have to operate mainly in the deamination direction. Hence, it would be essential for the intestine and liver to function cooperatively to detoxify ammonia to glutamine in B. sinensis exposed to environmental ammonia in seawater (Figure 1).

\section{CONVERSION OF GLUTAMINE TO UREA OR DETOXIFICATION OF AMMONIA TO CITRULLINE AND UREA?}

Differences in water and ionic regulation in seawater as opposed to freshwater may have rendered ammonotely disadvantageous in the marine environment (Campbell, 1973). However, it would be advantageous to accumulate urea as an osmolyte, and the function of the OUC in synthesizing urea for osmoregulatory purposes is seen today in elasmobranchs, holocephalans and coelacanths. Marine elasmobranchs are ureogenic because they possess a functional OUC in mitochondria of their livers and muscles (Anderson, 2001; Steele et al., 2005). They are also ureotelic, and urea is the primary product $(>50 \%)$ of nitrogen excretion. In order to be able 
to retain urea for osmoregulation, the effective urea permeability in these cartilaginous fishes is decreased. This is achieved as a result of the presence of specific secondarily active $\left(\mathrm{Na}^{+}\right.$coupled) urea transporters in gills and kidney and modification of lipid composition of gills to achieve higher cholesterol:phospholipid ratios (Fines et al., 2001; Walsh and Smith, 2001).

In ureogenic fishes, the OUC consists of the enzyme CPS III, ornithine transcarbamoylase (OTC), argininosuccinate synthetase, argininosuccinate lyase and arginase. The primary ammonia-fixing enzyme, GS, CPS III, and OTC are located in the matrix of liver mitochondria. CPS III utilizes glutamine as a substrate and therefore ureogenic fishes possess high levels of GS in liver mitochondria. Since $\mathrm{NH}_{3}$ is already detoxified to glutamine which is proton-neutral, the formation of carbamoyl phosphate via CPS III from glutamine in the liver mitochondrial matrix of fish cannot be regarded as an ammonia-detoxifying system (Figure 1). This is different from higher vertebrates, whose OUC involves CPS I which utilizes $\mathrm{NH}_{3}$ directly as a substrate. For marine elasmobranchs, the localization of GS and CPS III in the liver mitochondrial matrix (Anderson and Casey, 1984) probably evolved more as a mechanism for urea synthesis for osmoregulatory purposes (Ip et al., 2005b; Chew et al., 2006a). In this way, glutamine is utilized directly for carbamoyl phosphate, and ultimately urea synthesis, instead of exiting the mitochondria to act as a substrate for other anabolic purposes in the cytosol. The absence of aspartate transcarbamylase activity in the liver of spiny dogfish (Anderson, 1989) is consistent with this view as is the absence of glutamine from the blood serum of marine elasmobranchs (Leech et al., 1979). Working together, GS, CPS III, and OTC form citrulline in the matrix, which then exits the mitochondria (Figure 1). Citrulline is converted to arginine via argininosuccinate synthetase and argininosuccinate lyase in the cytosol. Unlike mammals, arginase is located in the mitochondrial matrix of fish (except lungfishes; Mommsen and Walsh, 1991); so, arginine has to re-enter the matrix where it is converted to urea, regenerating ornithine for citrulline synthesis (Mommsen and Walsh, 1991). Like glutamine, citrulline is proton-neutral (Campbell, 1991, 1997); so, uncoupling oxidative phosphorylation would not occur.

For those fishes which are ureogenic but non-ureosmotic, the OUC with the involvement of CPS III in the liver can be involved in converting glutamine into urea, a much smaller molecule, for excretion. The rates of urea synthesis and excretion increase in the giant mudskipper P. schlosseri (Ip et al., 2004c) and the slender lungfish Protopterus dolloi (Lim et al., 2004) within $24 \mathrm{~h}$ after feeding. Studies on marine sharks (Wood et al., 2005) and freshwater stingray (Chew et al., 2006a) confirm that ureogenic elasmobranchs also increase the rate of urea synthesis after feeding, although urea is retained for the purpose of osmoregulation instead of being excreted.

Only a few teleosts are ureotelic, excreting more than $50 \%$ of the nitrogenous wastes as urea (e.g., the gulf toadfish O. beta under confined or crowded conditions; Walsh et al., 1990), or able to detoxify a minor quantity of ammonia to urea during ammonia-loading (Mugilogobius abei; Iwata et al., 2000). Opsanus beta, in its natural habitat, appears to excrete roughly 50:50 mixture of ammonia and urea (Barimo et al., 2007) as part of an elaborate mechanism to cloak the scent of ammonia to predators by urea (Barimo and Walsh, 2006). The majority of tropical air-breathing teleosts studied so far do not use ureogenesis as a major strategy to deal with endogenous (during aerial exposure) or exogenous and endogenous ammonia (during ammonia-loading). These include the mudskippers $P$. schlosseri, B. boddarti, and Periophthalmus modestus (Iwata and Deguichi, 1995; Peng et al., 1998; Lim et al., 2001), the marble goby O. marmoratus (Jow et al., 1999), the four-eyed sleeper B. sinensis (Ip et al., 2001a; Anderson et al., 2002), the oriental weatherloach Misgurnus anguillicaudatus (Chew et al., 2001; Tsui et al., 2002), the mangrove killifish Rivulus marmoratus (Frick and Wright, 2002), the small snakehead Channa asiatica (Chew et al., 2003c), the swamp eel M. albus (Tay et al., 2003; Ip et al., 2004f) and the climbing perch Anabas testudineus (Tay et al., 2006) exposed to terrestrial conditions or ammonia-loading for various periods. Ureogenesis in fishes is energetically intensive. For teleosts and elasmobranchs, a total of 5 mol of ATP are hydrolyzed for each mole of urea synthesized, equivalent to 2.5 mol ATP used for each mole of nitrogen assimilated (Ip et al., 2001b). It is probably because of this that ureogenesis is not commonly adopted as a single major strategy to handle ammonia toxicity when air-breathing tropical teleosts (Chew et al., 2005b) are exposed to terrestrial conditions or environmental ammonia.

To date, the only adult teleost for which unequivocal evidence is available for the OUC to function primarily for the purpose of detoxifying ammonia to urea is the tilapia Alcolapia grahami in Lakes Magadi and Nakuru in Kenya. It thrives in a highly alkaline environment ( $\mathrm{pH} 10$ ), in which $\mathrm{NH}_{3}$ excretion would be totally impeded. As a result, it develops a high capacity to detoxify endogenous ammonia to urea via the OUC (Walsh et al., 1993). In fact, this is the first known example of complete ureotely in an entirely aquatic teleost fish (Randall et al., 1989). Alcolapia grahami contains in its liver significant levels of OUC enzymes and considerable GS activity. In addition, CPS III and all other OUC enzyme activities are present in the muscle at levels more than sufficient to account for the rate of urea excretion (Lindley et al., 1999). It is highly unusual that the muscle CPS can use $\mathrm{NH}_{3}$ as a substrate; but, because of this adaptation, there is no need for GS and OUC to be tightly coupled, and GS is not well expressed in muscle (Lindley et al., 1999). So, like the OUC in mammals, $\mathrm{NH}_{3}$ is directly converted via CPS and OTC to citrulline which exits the muscle mitochondria of A. grahami without uncoupling oxidative phosphorylation (Campbell, 1997). This is an important development for OUC to function primarily for ammonia detoxification, so that ammonia can be excreted as urea without being affected by the ambient alkaline water. The majority of the urea synthesized in A. grahami is excreted through the gills (Wood et al., 1994).

In contrast, African lungfishes, which belong to class: Sarcopterygii (lobe-finned fishes), despite being ammonotelic in water synthesize and accumulate urea during emersion and aestivation on land. African lungfishes are ureogenic and they possess a full complement of OUC enzymes (Janssens and Cohen, 1968; Mommsen and Walsh, 1989), including CPS III, in their livers (Chew et al., 2003b; Loong et al., 2005). Chew et al. (2004) demonstrated that the slender lungfish, $P$. dolloi, detoxified endogenous ammonia to urea, and the rate of urea synthesis increased 2.4- and 3.8-fold during 6 and 40 days (equivalent to 12 and 46 days, respectively, inclusive of the induction period), respectively, of aestivation in air. Subsequently, Loong et al. (2005) reported that the respective rates of urea synthesis in Protopterus aethiopicus and Protopterus annectens exposed to terres- 
trial conditions (without aestivation) for 6 days increased 1.2- and 1.5-fold, respectively. Why would African lungfish detoxify ammonia to urea? When urea is injected intraperitoneally into P. dolloi, only a small percentage (34\%) of it is excreted during the subsequent 24-h period (Ip et al., 2005c). At hour 24, significant quantities of urea are retained in various tissues of $P$. dolloi, which lead to an apparent reduction in endogenous ammonia production, a significant decrease in the hepatic arginine content, and a significantly lower level of brain tryptophan in this lungfish (Ip et al., 2005c). All these three phenomena have been observed previously in aestivating $P$. dolloi (Chew et al., 2004). So, increased urea synthesis and accumulation may have a physiological role in initiating and perpetuating aestivation in this lungfish (see Ip and Chew, 2010 for a review). Moreover, accumulation of urea in an aestivating lungfish may reduce the rate of evaporative water loss through vapor pressure depression.

\section{PASSAGE OF AMMONIA ACROSS THE BLOOD-BRAIN BARRIER AND INTO BRAIN CELLS - POSSIBLE REASONS FOR HIGH AMMONIA TOLERANCE IN CERTAIN FISH SPECIES}

Once endogenous or exogenous ammonia enters the blood, it would exert toxic effects on all cells, particularly the heart and the brain which are vital organs with excitable cell types. However, at least for rainbow trout, the heart does not seem to be the organ where ammonia toxicity acts (Tsui et al., 2004), and that leaves the brain as the main target of ammonia toxicity in fish. Since the blood-brain barrier permeability for ${ }^{13} \mathrm{NH}_{4}^{+}$is only $\sim 0.5 \%$ that of ${ }^{13} \mathrm{NH}_{3}$ in Rhesus monkey (Raichle and Larson, 1981), the traditional assumption is that $\mathrm{NH}_{3}$ can pass the blood-brain barrier by diffusion, and $\mathrm{NH}_{4}^{+}$translocation can be neglected (Cooper and Plum, 1987). However, effects of $\mathrm{pH}$ on ammonia uptake are often less pronounced than expected, although they are in the direction predicted by the $\mathrm{NH}_{3}$ diffusion hypothesis. Therefore, it has been proposed recently that $\mathrm{NH}_{4}^{+}$can also permeate the blood-brain barrier with the possible involvement of Rh glycoproteins, $\mathrm{Na}^{+}$/ $\mathrm{K}^{+}$-ATPase, barium-inhibitable $\mathrm{K}^{+}$channel and bumetanide inhibitable $\mathrm{Na}^{+}: \mathrm{K}^{+}: 2 \mathrm{Cl}^{-}$cotransporter (Ott and Larsen, 2004; Figure 2). Once $\mathrm{NH}_{3}$ or $\mathrm{NH}_{4}^{+}$get through the blood-brain barrier, they can permeate the plasma membrane of brain cells through various transporter proteins. It has been demonstrated that astrocytes can down-regulate the gene expression of several transporters, which include the gap-junction channel connexin 43, the water channel aquaporin 4 and the astrocytic inward-rectifying potassium channel genes (Kir4.1 and Kir5.1), in its plasma membrane in response to hyperammonemia (Lichter-Konecki et al., 2008).

In mammals, high levels of brain ammonia $\left(1-3 \mathrm{mmol}^{-1}\right)$ lead to glutamatergic dysfunction (Felipo and Butterworth, 2002; Rose, 2002) which remains as the leading candidate in the pathogenesis of hepatic encephalopathy in acute liver failure. However, many tropical air-breathing fishes (see Ip et al., 2004b; Chew et al., 2006b for reviews) can tolerate high levels of environmental ammonia, and these environmental tolerance correlate well with their high tolerance of ammonia at the cellular and sub-cellular levels (Ip et al., 2005a). This adaptation facilitates the accommodation of relatively high concentrations of ammonia in the blood, which can reduce the net influx of $\mathrm{NH}_{3}$ by lowering the inwardly directed $\Delta \mathrm{P}_{\mathrm{NH}_{3}}$ during ammonia-loading. In addition, a build up of ammonia in the body may be a prerequisite for volatilization of $\mathrm{NH}_{3}$ in certain air-breathing fish species (Tsui et al., 2004). At present, no information is available on the permeability of the fish blood-brain barrier to $\mathrm{NH}_{3}$ and $\mathrm{NH}_{4}^{+}$, but the brain ammonia content of certain fish species can build up to very high levels under certain conditions (see review by Chew et al., 2006). Therefore, future studies should focus on the expression of ammonia transporters in and the regulation of $\mathrm{NH}_{4}^{+}$fluxes across the blood-brain barrier and the plasmalemma of cells in the brain of these fishes.

The administration of (5R,10S)-(+)-methyl-10,11-dihydro-5Hdibenzo[a,d]cyclohepten-5,10-imine hydrogen maleate (MK801), which is an antagonist of NMDA receptors, at a dosage of $2 \mu \mathrm{g} \mathrm{g}^{-1}$ fish has no protective effect on P. schlosseri and B. boddarti injected with a lethal dose of ammonium acetate, indicating that activation of NMDA receptors is not the major cause of death during acute ammonia intoxication (Ip et al., 2005a). Thus, unlike mammals (Marcaida et al., 1992; Kosenko et al., 2000), activation of NMDA receptors may not be the explanation for acute ammonia toxicity in the brains of P. schlosseriand B. boddarti. Since membrane depolarization can lead to the removal of the $\mathrm{Mg}^{2+}$ block on NMDA receptors and result in their activation (Fan and Szerb, 1993), it would appear that these mudskippers have special abilities to control the intracellular ammonia level in their brains despite drastic increases in brain ammonia contents (intracellular + extracellular). $\mathrm{NH}_{4}^{+}$can replace $\mathrm{K}^{+}$in the facilitated diffusion of $\mathrm{K}^{+}$through $\mathrm{K}^{+}$channels and/ or active transport of $\mathrm{K}^{+}$through $\mathrm{Na}^{+} / \mathrm{K}^{+}$-ATPase; both these processes have direct or indirect deleterious effects on the membrane potential of a cell. In view of the high levels of ammonia in the brains of P. schlosseri and B. boddarti exposed to chronic and acute ammonia toxicity and the lack of protective effect from MK801, it can be deduced that either membrane depolarization occurred but did not lead to activation of NMDA receptors, or membrane potentials were resilient to $\mathrm{NH}_{4}^{+}$interference due to the presence of $\mathrm{K}^{+}$channels and $\mathrm{Na}^{+} / \mathrm{K}^{+}$-ATPase with high substrate specificities for $\mathrm{K}^{+}$, in the brains of these two mudskippers, the confirmation of which awaits future studies.

\section{PASSAGE OF AMMONIA ACROSS BRANCHIAL AND CUTANEOUS SURFACES - ACTIVE EXCRETION OF AMMONIA AND REDUCTION IN AMMONIA INFLUX TO DEFEND AGAINST AMMONIA TOXICITY \\ ACTIVE TRANSPORT OF $\mathrm{NH}_{4}^{+}$}

Theoretically, the most effective way to defend against ammonia toxicity in fish in alkaline water, during emersion or when exposed to ammonia-loading conditions is active transport of $\mathrm{NH}_{4}^{+}$(as have been suggested for the inner mitochondrial membrane of ammonotelic fishes; Campbell, 1997), because it facilitates the maintenance of low internal ammonia levels and prevents the brain from ammonia toxicity. Indeed, some air-breathing tropical fishes with modified gill structures or accessory breathing organs are capable of doing so (the giant mudskipper, Randall et al., 1999; Chew et al., 2003a; Ip et al., 2004d; the African sharptooth catfish, Ip et al., 2004e; the climbing perch, Tay et al., 2006).

The gills of the giant mudskipper $P$. schlosseri are specially adapted for terrestrial survival (Ip et al., 1993; Kok et al., 1998) because of its specialized gill morphology and morphometry (Low et al., 1988, 1990; Wilson et al., 1999, 2000). There are intrafilamentous interlamellar fusions in its gills, which form numerous 
fenestrae on the surface of the gill filament. When $8 \mu \mathrm{mol} \mathrm{g}{ }^{-1}$ ammonium acetate was injected intraperitoneally into $P$. schlosseri followed with $24 \mathrm{~h}$ of aerial exposure, the cumulative ammonia excreted was significantly greater than the saline-injected control (Chew et al., 2007). At hour 2, the ammonia excretion rate in the experimental fish was transiently greater than that in fish kept in water. By hour 6, a large portion (33\%) of the injected ammonia was excreted by the experimental fish through the head region, probably through the gills (Chew et al., 2007). Because ammonia could be excreted only into the small amount of water trapped in the fenestrae of the fused secondary lamellae in the gills of P. schlosseri during emersion, ammonia concentration build up quickly therein and reached high level $\left(\sim 90 \mathrm{mmol}^{-1}\right)$. So, P. schlosserican effectively excrete a high load of ammonia on land, which indirectly supports the proposition that active $\mathrm{NH}_{4}^{+}$excretion contributes in part to its high terrestrial affinity and high tolerance of aerial exposure.

In addition, $P$. schlosseri can maintain an unchanged ammonia excretion rate when exposed to alkaline water (Chew et al., 2003a). It can also tolerate very high concentrations of environmental ammonia (>100 $\mathrm{mmol}^{-1} \mathrm{NH}_{4} \mathrm{Cl}$; Ip et al., 1993; Peng et al., 1998). When exposed to environmental ammonia, P. schlosseri is able to maintain low concentrations of ammonia in its plasma (Peng et al., 1998; Randall et al., 1999) as a result of its ability to actively excrete ammonia against large inward $\mathrm{NH}_{3}$ and $\mathrm{NH}_{4}^{+}$ gradients (up to at least $30 \mathrm{mmol} \mathrm{l}^{-1} \mathrm{NH}_{4} \mathrm{Cl}, \mathrm{pH} 7.2$; Randall et al., 1999). The mechanisms apparently involve $\mathrm{Na}^{+} / \mathrm{K}^{+}\left(\mathrm{NH}_{4}^{+}\right)$-ATPase at the basalemma and $\mathrm{Na}^{+} / \mathrm{H}^{+}\left(\mathrm{NH}_{4}^{+}\right)$exchangers at the apical membrane of the branchial epithelia. $\mathrm{NH}_{4}^{+}$substitutes for $\mathrm{K}^{+}$in a number of ion transport proteins owing to similarity in their hydration radii. Indeed, active ammonia excretion in $P$. schlosseri exposed to environmental ammonia is sensitive to ouabain, an inhibitor of $\mathrm{Na}^{+} / \mathrm{K}^{+}$-ATPase, and $\mathrm{NH}_{4}^{+}$can replace $\mathrm{K}^{+}$as a substrate for ATPase activity in vitro (Randall et al., 1999). Moreover, the addition of amiloride, an inhibitor of NHE, to the external medium decreases the rate of ammonia excretion in P. schlosseri (Randall et al., 1999). NHE2- and NHE3-like proteins have been shown to be present in the apical crypts of branchial mitochondria-rich cells (Wilson et al., 2000). Since plasma $\mathrm{Na}^{+}$level increases in specimens exposed to high concentrations of environmental ammonia (Randall et al., 1999), $\mathrm{NH}_{4}^{+}$must be actively transported across the branchial epithelium in exchange with $\mathrm{Na}^{+}$. The possibility of $\mathrm{NH}_{3}$ trapping in the active excretion of ammonia can be eliminated because the addition of buffer to the medium, which removes the acid boundary layer, has no effect on the rate of ammonia excretion (Wilson et al., 2000; Ip et al., 2004d). Also the addition of bafilomycin A1, a vesicular-type $\mathrm{H}^{+}$-ATPase inhibitor, significantly decreases the net acid flux but has no effect on the rate of ammonia excretion (Ip et al., 2004d). The possible role of $\mathrm{Rh}$ glycoproteins in active $\mathrm{NH}_{4}^{+}$excretion in the giant mudskipper is uncertain at present, but Weihrauch et al. (2009) has speculated that these proteins are expressed at high levels in the gills through which $\mathrm{NH}_{3}$ is transported out of the fish along with $\mathrm{CO}_{2}$.

\section{LOWERING OF ENVIRONMENTAL pH}

For fishes living in stagnant water of a finite volume (puddle, tidepool, or water-filled burrow) it is possible for the acidifying effects of their excretions of $\mathrm{H}^{+}$and $\mathrm{CO}_{2}$ to have a significant impact on environmental $\mathrm{pH}$. This lowering of environmental $\mathrm{pH}$ has advantages for dealing with elevations in environmental ammonia levels by reducing the concentration of $\mathrm{NH}_{3}$, the more permeant species of ammonia, constituting "environmental ammonia detoxification" (Chew et al., 2003a).

Mudskippers build burrows on the mud flat, and lay eggs therein during the breeding season. In one study, the $\mathrm{pH}$ of the water in a canal that supplied water to a mud flat was 7.84 , yet the $\mathrm{pH}$ of the water sampled from burrows of the giant mudskipper P. schlosseri was close to 7.0 (Ip et al., 2004d). This indicates that P. schlosseri modifies the $\mathrm{pH}$ of the burrow water, confirming laboratory observations made by Chew et al. (2003a). Lowering the $\mathrm{pH}$ of the burrow water from 8.3 ( $\mathrm{pH}$ of full strength seawater) to 7.0 increases the ratio of $\mathrm{NH}_{4}^{+}$to $\mathrm{NH}_{3}$, which lowers the toxicity of $\mathrm{NH}_{3}$ to the fish and embryos in the burrows. When P. schlosseri is kept in 10 volumes (w/v) of $50 \%$ seawater with $2 \mathrm{mmol} \mathrm{l}^{-1}$ of Tris- $\mathrm{HCl}$ at $\mathrm{pH} 8.5$ or 9.0 , the decrease in $\mathrm{pH}$ is large and rapid (Chew et al., 2003a; Ip et al., 2004d). Thus, large quantities of acid must be excreted to manipulate the external $\mathrm{pH}$ of alkaline waters. More importantly, P. schlosseri is capable of increasing the rate of net acid excretion in response to the presence of 20 or $30 \mathrm{mmol} \mathrm{l}^{-1} \mathrm{NH}_{4} \mathrm{Cl}$ in the water at $\mathrm{pH} 7.0$ or 8.0 (Ip et al., 2004d). This represents direct evidence linking net acid excretion with defense against environmental ammonia toxicity in P. schlosseri.

As a result of active excretion of $\mathrm{NH}_{4}^{+}$into a finite volume of water in the burrow, the ambient ammonia concentration increases. Therefore, it is imperative for the excreted $\mathrm{NH}_{4}^{+}$not to dissociate into $\mathrm{NH}_{3}$ and $\mathrm{H}^{+}$, because $\mathrm{NH}_{3}$ would diffuse back into the body down an inwardly directed $\Delta \mathrm{P}_{\mathrm{NH}_{3}}$. Because acid excretion is responsive to environmental ammonia, there is a continuous excretion of acid even at neutral $\mathrm{pH}$. This would maintain a low $\mathrm{pH}$ (high concentrations of $\mathrm{H}^{+}$) in the boundary water layer of the branchial epithelia, preventing the excreted $\mathrm{NH}_{4}^{+}$from dissociating into $\mathrm{NH}_{3}$ and $\mathrm{H}^{+}$, and avoiding back flux of $\mathrm{NH}_{3}$. In essence, this is the process of " $\mathrm{NH}_{4}^{+}$trapping". Indeed, both active $\mathrm{NH}_{4}^{+}$excretion and $\mathrm{H}^{+}$ excretion take place in the head region of $P$. schlosseri, where the gills and the opercular membranes are located (Ip et al., 2004d). It is essential for these two mechanisms to be located together, because the branchial and opercular surfaces have the important functions of allowing passage of gases and other ions. Excretion of acid to trap the actively excreted $\mathrm{NH}_{4}^{+}$is likely to be more effective than modifying the fluidity of these surfaces to change the permeability of $\mathrm{NH}_{3}$, which would also affect the permeability of other gaseous molecules.

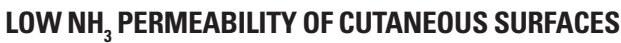

The branchial epithelial surface of aquatic teleosts has a higher permeability to $\mathrm{NH}_{3}$ due to its major function in gaseous exchange. Since air-breathing fishes depend largely on the accessory breathing organ for respiration, their gills are usually degenerate (Graham, 1997). Moreover, they usually hold air in their buccal cavities during immersion, which means their gills would not be exposed to the external medium, and $\mathrm{NH}_{3}$ excretion through the gills would be relatively ineffective. However, many tropical air-breathing fishes substitute branchial respiration with cutaneous respiration by having highly vascularized skins. Therefore, a substantial portion of 
ammonia excretion takes place through the cutaneous surface of air-breathing fishes (Graham, 1997), and fish skin is known to express Rh glycoproteins (see Weihrauch et al., 2009 for a review). For fishes which are exposed frequently to environmental ammonia, it would be essential for them to reduce the permeability of their skins to $\mathrm{NH}_{3}$ despite the cell membranes being permeable to gaseous molecules like $\mathrm{O}_{2}$ and $\mathrm{CO}_{2}$, even though the permeability of $\mathrm{NH}_{3}$ is less than those of $\mathrm{O}_{2}$ and $\mathrm{CO}_{2}$ (Marcaggi and Coles, 2001). Moreover, under ammonia-loading conditions, it would be essential to reduce or suppress the expression of transporters that would facilitate ammonia transport in the skin of these fishes. Although it has been reported that Rhcg1 gene expression increases in the skin of the mangrove killifish, K. marmoratus, exposed to environmental ammonia (Hung et al., 2007), it is important to take note that this fish, unlike many others, is capable of volatilizing ammonia through its skin under certain conditions (Frick and Wright, 2002).

A certain amount of $\mathrm{NH}_{3}$ permeates the membrane by solvation and diffusion in the lipid bilayer. The lipid-water partition coefficient for ammonia is low (Evans and Cameron, 1986), suggesting that membrane permeability to ammonia is generally low. In certain biological situations, however, membrane permeability to ammonia is further reduced (Kikeri et al., 1989), and several mechanisms for reducing the permeability of membranes to ammonia are apparent from model studies. In particular, the cholesterol and phospholipid fatty acid contents of artificial membranes have been shown to affect the permeability or artificial membranes to ammonia (Lande et al., 1995). When a fish is confronted with ammonia-loading conditions, a reduction in $\mathrm{NH}_{3}$ permeability of the skin would help reduce the influx of $\mathrm{NH}_{3}$. In the giant mudskipper, this is an important adaptation which complements active $\mathrm{NH}_{4}^{+}$excretion through its gills (Randall et al., 1999; Ip et al., 2004d), because it would prevent a back diffusion of $\mathrm{NH}_{3}$ through the cutaneous surfaces after the build up of high ammonia concentrations in the external medium (Ip et al., 2004d).

Indeed, the flux of $\mathrm{NH}_{3}$ through the skin of P. schlosseri in an Ussing-like apparatus at $25^{\circ} \mathrm{C}$ down a 10 -fold $\mathrm{NH}_{4} \mathrm{Cl}$ gradient between two media with 1 unit $\mathrm{pH}$ difference $(\mathrm{pH} 8 \rightarrow \mathrm{pH} 7)$ is

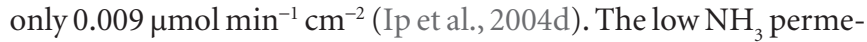
ability in the skin of P. schlosseri is likely due to its low membrane fluidity (Lande et al., 1995). The phosphatidylcholine:phosphati dylethanolamine ratio, an indication of membrane fluidity from the skin of P. schlosseri is 3.4, much higher than those of tissues of other fish species (Hazel and Landrey, 1988). Furthermore, the skin of $P$. schlosseri has very high cholesterol content $\left(4.5 \mu \mathrm{mol} \mathrm{g}{ }^{-1}\right)$, which lowers the fluidity of biomembranes. The cholesterol content in the skin of P. schlosseri increased significantly to $5.5 \mu \mathrm{mol} \mathrm{g}{ }^{-1}$ after 6 days of ammonia exposure (Ip et al., 2004d), suggesting a role for cholesterol as a defense mechanism against environmental ammonia toxicity.

African lungfishes which can tolerate at least $100 \mathrm{mmol} \mathrm{l}^{-1}$ $\mathrm{NH}_{4} \mathrm{Cl}$ may also have low permeability to $\mathrm{NH}_{3}$ in the skin. Chew et al. (2005b) estimated the flux of $\mathrm{NH}_{3}$ through the skin of $P$.

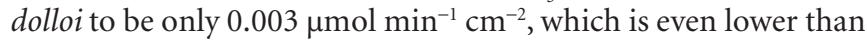
that of the giant mudskipper $P$. schlosseri. Subsequently, Loong et al. (2007) reported that the skin of P. aethiopicus also had low permeability to $\mathrm{NH}_{3}$ in an Ussing-like apparatus. Indeed, the influx of exogenous ammonia into fish exposed to $30 \mathrm{mmol} \mathrm{l}^{-1}$
$\mathrm{NH}_{4} \mathrm{Cl}$ was low $\left(0.117 \mu \mathrm{mol} \mathrm{m^{-1 }} 100 \mathrm{~g}^{-1}\right.$ fish $)$. As a result, $P$. aethiopicus could afford to maintain relatively low ammonia contents in its plasma, muscle, liver and brain even after 6 days of exposure to $100 \mathrm{mmol} \mathrm{l}^{-1} \mathrm{NH}_{4} \mathrm{Cl}$. Surprisingly, fish exposed to 30 or $100 \mathrm{mmol} \mathrm{l}^{-1} \mathrm{NH}_{4} \mathrm{Cl}$ had comparable ammonia contents in the muscle and the brain in spite of the big difference $\left(70 \mathrm{mmol}^{-1}\right)$ in environmental ammonia concentrations. Results of Loong et al. (2007) suggest that $P$. aethiopicus was capable of decreasing the $\mathrm{NH}_{3}$ permeability of its body surface when exposed to high concentrations of environmental ammonia. Indeed, after 6 days of exposure to $100 \mathrm{mmol} \mathrm{l}^{-1} \mathrm{NH}_{4} \mathrm{Cl}$ the $\mathrm{NH}_{3}$ permeability constant of the skin decreased to half of that of the control. A decrease in the already low cutaneous $\mathrm{NH}_{3}$ permeability and an increased urea synthesis, working in combination, allowed P. aethiopicus to effectively defend against environmental ammonia toxicity without elevating the plasma ammonia level. Therefore, unlike other fishes, glutamine and alanine contents did not increase in the muscle and liver, and there was no accumulation of glutamine in the brain, even when the fish was immersed in water containing $100 \mathrm{mmol} \mathrm{l}^{-1} \mathrm{NH}_{4} \mathrm{Cl}$.

\section{VOLATILIZATION OF $\mathrm{NH}_{3}$}

Since ammonia can exist as $\mathrm{NH}_{3}$ gas, it is logical that certain fish may be able to excrete $\mathrm{NH}_{3}$ directly into the atmosphere. In teleosts, ammonia volatilization was first reported in the temperate intertidal blenny (Blennius pholis), but it only accounted for $8 \%$ of the total ammonia excreted during emersion (Davenport and Sayer, 1986). However, the ammonotelic tropical fishes Alticus kirki (the leaping blenny) (Rozemeijer and Plaut, 1993), K. marmoratus (the mangrove killifish) (Frick and Wright, 2002), and M. anguillicaudatus (the oriental weatherloach) (Tsui et al., 2002) are capable of volatilizing significant amounts of ammonia during aerial exposure. High temperatures and humidity increase the likelihood of the ammonia excreted into the film of water covering the body surface of tropical fishes being volatilized.

In the case of $M$. anguillicaudatus, ammonia built up to very high levels in the muscle $\left(14.8 \mu \mathrm{mol} \mathrm{g}^{-1}\right)$, liver $\left(15.2 \mu \mathrm{mol} \mathrm{g}^{-1}\right)$, and plasma $\left(5.09 \mu \mathrm{mol} \mathrm{ml}^{-1}\right)$ after $48 \mathrm{~h}$ of emersion (Chew et al., 2001). Building up of internal ammonia may be an essential prerequisite for volatilization to occur. The blood $\mathrm{pH}$ simultaneously becomes more alkaline; this would lead to a high level of $\mathrm{NH}_{3}$ in the blood. It is possible that a much higher $\Delta \mathrm{P}_{\mathrm{NH}_{3}}$ gradient is required to facilitate the efflux of ammonia through non-branchial epithelial surfaces. In M. anguillicaudatus, there appears to be at least two sites of $\mathrm{NH}_{3}$ volatilization, i.e., the skin and the digestive tract, under terrestrial conditions. During emersion, the surface of the skin becomes significantly more alkaline (Tsui et al., 2002). Moreover, the $\mathrm{pH}$ of the water underneath the fish is significantly higher than that of the submerged control. Since the fraction of $\mathrm{NH}_{3}$ present is strongly influenced by the $\mathrm{pH}$ of the medium, the skin of $\mathrm{M}$. anguillicaudatus can be a site of $\mathrm{NH}_{3}$ volatilization. Simultaneously, the $\mathrm{pH}$ of the mucosal surface of the anterior portion of the digestive tract becomes significantly more alkaline in M. anguillicaudatus exposed to terrestrial conditions (Tsui et al., 2002). Although the skin and the digestive tract may both be involved in $\mathrm{NH}_{3}$ volatilization when the fish is moving on land, excretion of ammonia through the skin would be ineffective when the fish burrows into the mud. In the 
mud, maintaining the skin surface or the surrounding film of water at $\mathrm{pH} 8$ would aggravate the situation, because of the reversed $\Delta \mathrm{P}_{\mathrm{NH}_{3}}$ gradient. When the fish is surrounded by mud, the digestive tract (either through the mouth or the cloaca) becomes the only avenue for $\mathrm{NH}_{3}$ volatilization to occur.

Recently, Moreira-Silva et al. (2010) reported an increase in membrane fluidity, which would presumably enhance $\mathrm{NH}_{3}$ permeation through the plasma membrane, of the gills of M. anguillicaudatus exposed to terrestrial conditions. Additionally, there was a significant increase in the mRNA expression of the ammonia transport protein, Rhcg1 (Slc42a3), in the gills during aerial exposure. The colocalization of $\mathrm{H}^{+}$-ATPase and Rhcg1 to the same cell type suggested a role for $\mathrm{H}^{+}$-ATPase in ammonia excretion via Rhcgl by $\mathrm{NH}_{4}^{+}$trapping (Figure 4), confirming the importance of gill boundary layer acidification in net ammonia excretion in this fish. By contrast, there was no significant change in the mRNA expression of Rhcg1 in the gills of M. anguillicaudatus exposed to high concentrations of environmental ammonia.

As for K. marmoratus, the cutaneous surface is alkalinized by 0.4-0.5 pH units during emersion, promoting the accumulation of $\mathrm{NH}_{3}$ on the skin surface (Litwiller et al., 2006). Hung et al. (2007) demonstrated Rh glycoprotein mRNA expression in the gills and skin and verified that its expression was sensitive to both increased environmental ammonia concentrations and air exposure. Since Rhcgl and Rhcg2 expression increased many fold in the skin following air exposure, Hung et al. (2007) concluded that Rhc glycoproteins promoted $\mathrm{NH}_{3}$ passage from the blood to skin surface during emersion.

\section{CONCLUSION}

Ammonia is produced mainly in fish hepatocytes and must exit the mitochondrial matrix to be excreted through the gills. Efforts should be made in the future to elucidate the form and mecha-

\section{REFERENCES}

Albrecht, J., and Norenberg, M. D. (2006). Glutamine: a Trojan horse in ammonia neurotoxicity. Hepatology 44, 788-794.

Anderson, P. M. (1989). Glutaminedependent carbamoyl-phosphate synthetase and other enzyme activities related to the pyrimidine pathway in spleen of Squalus acanthias. Comp. Biochem. Physiol. 85B, 783-788.

Anderson, P. M. (2001). "Urea and glutamine synthesis: environmental influences on nitrogen excretion," in Fish Physiology, Vol. 20, Nitrogen Excretion, eds P. A. Wright and P. M. Anderson (New York: Academic Press), 239-277.

Anderson, P. M., Broderius, M. A., Fong, K. C., Tsui, T. K. N., Chew, S. F., and Ip, Y. K. (2002). Glutamine synthetase expression in liver, muscle, stomach and intestine of Bostrichyths sinensis in response to exposure to a high exogenous ammonia concentration. J. Exp. Biol. 205, 2053-2065.
Anderson, P. M., and Casey, C. A. (1984). Glutamine-dependent synthesis of citrulline by isolated hepatic mitochondria from Squalus acanthias. J. Biol. Chem. 259, 456-462.

Arillo, A., Margiocco, C., Melodia, F., Ammonia toxicity mechanisms in fish: studies on rainbow trout (Salmo gairdneri Rich). Ecotoxicol. Environ. Saf. 5, 316-325.

Avella, M., and Bornancin, M. (1989). A new analysis of ammonia and sodium transport through the gills of the freshwater rainbow trout (Salmo gairdneri). J. Exp. Biol. 142, 155-175.

Bakouh, N., Benielloun, F., Cherif-Zahar, B., and Planelles, G. (2006). The challenge of understanding ammonium homeostasis and the role of $\mathrm{Rh}$ glycoproteins. Transfus. Clin. Biol. 13, 139-146.

Ballantyne, J. S. (2001). "Amino acid metabolism," in Fish Physiology, Vol. 19, Nitrogen Excretion, eds P. A. Mensi, P., and Schenone, G. (1981).

nisms involved in the permeation of ammonia through the inner mitochondrial membrane without disrupting the $\mathrm{H}^{+}$gradient. Ammonia exerts its toxic effects on the brains of vertebrates, but the brains of certain fish species can tolerate high concentrations of ammonia and glutamine, the latter of which is a Trojan horse of ammonia toxicity in mammalian brains. Hence, it would be essential to investigate the permeation of ammonia through the blood-brain barrier of these fishes. Additionally, it would be meaningful to examine how glutamine and ammonia permeation through the mitochondrial membranes are regulated in the brain cells of these fishes, and to determine the level of glutaminase activity present in these mitochondria. Results obtained from these fishes may provide new insights into mechanisms of ammonia toxicity, and shed light on how ammonia toxicity to vertebrate brains can be ameliorated. Defense against ammonia toxicity in fishes under adverse environmental conditions can be achieved through the detoxification of ammonia involving enzymes present in the mitochondria or cytosol and/or the enhancement of effectiveness of $\mathrm{NH}_{3} / \mathrm{NH}_{4}^{+}$excretion through the branchial and cutaneous epithelia. While the involvement of $\mathrm{Rh}$ glycoproteins in ammonia excretion through fish gills and skins has been established, their functional roles in active $\mathrm{NH}_{4}^{+}$excretion in some fish species with high environmental ammonia tolerance are uncertain at present. Future studies on mechanisms involved in active $\mathrm{NH}_{4}^{+}$excretion through the gills and/or skin of these fishes would provide insights into novel therapeutic measure to handle patients with hyperammonemia.

\section{ACKNOWLEDGEMENT}

This work was supported in part by the Ministry of Education of the Republic of Singapore through grants R-154-000-409-112 and R-154-000-470-112 to Y. K. Ip, and NIE Academic Research Fund RI9/08 CSF to S. F. Chew.

Wright and P.M.Anderson (New York: Academic Press), 77-107.

Barimo, J. F., and Walsh, P. J. (2006). Use of urea as a chemosensory cloaking molecule by a bony fish. J. Exp. Biol. 209, 4254-4261.

Barimo, J. F., Serafy, J. E., Frezza, P. E., and Walsh, P. J. (2007). Habitat use, urea production and spawning in the gulf toadfish Opsanus beta. Mar. Biol. 150, 497-508.

Bever, K., Chenoweth, M., and Dunn, A. (1981). Amino acid gluconeogenesis and glucose turnover in kelp bass (Paralabrax sp.) Am. J. Physiol. 240, R246-R252.

Binstock, L., and Lecar, H. (1969). Ammonium ion currents in the squid giant axon. J. Gen. Physiol. 53, 342-361.

Braun, M. H., Steele, S. L., and Perry, S. F. (2009). Nitrogen excretion in developing zebrafish (Danio rerio): a role for $\mathrm{Rh}$ proteins and urea transporters. Am. J. Physiol. Renal Physiol. 296, F994-F1005.
Brierly, G. P., and Stoner, C. D. (1970). Swelling and contraction of heart mitochondria suspended in ammonium chloride. Biochemistry 9, 708-713.

Brusilow, S.W. (2002). Hyperammonemic encephalopathy. Medicine 81 , 240-249.

Brusilow, S. W., and Traystman, R. J. (1986). Letter to editor. N. Engl. J. Med. 314, 786.

Buddington, R. K., Krogdahl, A., and BakkeMcKellep, A. M. (1997). The intestines of carnivorous fish: structure and functions and the relations with diet. Acta Physiol. Scand. 161, 67-80.

Calamita, G., Ferri, D., Gena, P., Liquori, G. E., Cavalier, A., Thomas, D., and Svelto, M. (2005). The inner mitochondrial membrane has aquaporin-8 water channels and is highly permeable to water. J. Biol. Chem. 280, 17149-17153.

Calamita, G., Gena, P., Meleleo, D., Ferri, D., and Svelto, M. (2006). Water per- 
meability of rat liver mitochondria: a biophysical study. Biochim. Biophys. Acta 1758, 1018-1024.

Campbell, J. W. (1973). "Excretory nitrogen metabolism," in Comparative Animal Physiology, 3rd Edn., ed. C. L. Prosser (Philadelphia: Saunders College Publishing), 279-316.

Campbell, J. W. (1991). "Excretory nitrogen metabolism" in Environmental and Metabolic Animal Physiology. Comparative Animal Physiology, 4th Edn., ed. C. L. Prosser (New York: Wiley-Interscience), 277-324.

Campbell, J. W. (1997). Mitochondrial ammonia metabolism and the proton-neutral theory of hepatic ammonia detoxication. J. Exp. Zool. 278, 308-321.

Campbell, J.W., Aster, P.A., and Vorhaben, J.E. (1983). Mitochondrial ammoniagenesis in liver of the channel catfish Ictalurus punctatus. Am. J. Physiol. 244, R709-R717.

Chew, S. F., Chan, N. K. Y., Tam, W. L., Loong, A. M., Hiong, K. C., and Ip, Y. K. (2004). The African lungfish, Protopterus dolloi, increases the rate of urea synthesis despite a reduction in ammonia production during 40 days of aestivation in a mucus cocoon. $J$. Exp. Biol. 207, 777-786.

Chew, S. F., Gan, J., and Ip, Y. K. (2005a). Nitrogen metabolism and excretion in the swamp eel, Monopterus albus, during 6 or 40 days of aestivation in mud. Physiol. Biochem. Zool. 78, 620-629.

Chew, S. F., Ho, L., Ong, T. F., Wong, W. P., and Ip, Y. K. (2005b). The African lungfish, Protopterus dolloi, detoxifies ammonia to urea during environmental ammonia exposure. Physiol. Biochem. Zool. 78, 31-39.

Chew, S. F., Hong, L. N., Wilson, J. M., Randall, D. J., and Ip, Y. K. (2003a). Alkaline environmental $\mathrm{pH}$ has no effect on the excretion of ammonia in the mudskipper Periophthalmodon schlosseri but inhibits ammonia excretion in the related species Boleophthalmus boddaerti. Physiol. Biochem. Zool. 76, 204-214.

Chew, S. F., Ong, T. F., Ho, L., Tam, W. L., Loong, A. M., Hiong, K. C., Wong, W. P., and Ip, Y. K. (2003b). Urea synthesis in the African lungfish Protopterus dolloi-hepatic carbamoyl phosphate synthetase III and glutamine synthetase can be up-regulated by 6 days of aerial exposure. J. Exp. Biol. 206, 3615-3624.

Chew, S. F., Wong, M. Y., Tam, W. L., and Ip, Y. K. (2003c). The snakehead Channa asiatica accumulates alanine during aerial exposure, but is incapable of sustaining locomotory activities on land through partial amino acid catabolism. J. Exp. Biol. 206, 693-704.

Chew, S. F., Jin, Y., and Ip, Y. K. (2001). The loach Misgurnus anguillicaudatus reduces amino acid catabolism and accumulates alanine and glutamine during aerial exposure. Physiol. Biochem. Zool. 74, 226-237.

Chew, S. F., Poothodiyil, N. K., Wong, W. P., and Ip, Y. K. (2006a). Exposure to brackish water leads to increases in conservation of nitrogen and retention of urea in the Asian freshwater stingray, Himantura signifer, upon feeding. J. Exp. Biol. 209, 484-492.

Chew, S. F., Wilson, J. M., Ip, Y. K., and Randall, D. J. (2006b). "Nitrogenous excretion and defense against ammonia toxicity," in Fish Physiology, Vol. 23, The Physiology of Tropical Fishes, eds V. Val, V. Almedia-Val, and D. J. Randall (New York: Academic Press), 307-395.

Chew, S. F., Sim, M. Y., Phua, Z. C., Wong, W. P., and Ip, Y. K. (2007). Active ammonia excretion in the giant mudskipper, Periophthalmodon schlosseri (Pallas), during emersion. J. Exp. Zool. 307A, 357-369.

Chew, S. F., Tng, Y.Y.M., Wee, N. L. J., Tok, C.Y., Wilson, J.M., and Ip, Y. K. (2010). Intestinal osmoregulatory acclimation and nitrogen metabolism in juveniles of the freshwater marble goby exposed to seawater. J. Comp. Physiol. B 180, 511-520.

Chew, S. F., Tng, Y. Y. M., Wee, N. L. J., Wilson, J. M., and Ip, Y. K. (2009). Nitrogen metabolism and branchial osmoregulatory acclimation in the juvenile marble goby, Oxyeleotris marmorata, exposed to seawater. Comp. Biochem. Physiol. A 154, 360-369.

Choe, H, Sackin, B., and Palmer, L. G. (2000). Permeation properties of inward-rectifier potassium channels and their molecular determinants. $J$. Gen. Physiol. 115, 391-404.

Ching, B. Y., Chew, S. F., Wong, W. P., and Ip, Y. K. (2009). Environmental ammonia exposure induces oxidative stress in gills and brain of Boleophthalmus boddarti (mudskipper). Aquat. Toxicol. 95, 203-212.

Cooper, J. L., and Plum, F. (1987). Biochemistry and physiology of brain ammonia. Physiol. Rev. 67, 440-519.

Dabrowska, H., and Wlasow, T. (1986). Sublethal effect of ammonia on certain biochemical and haematological indicators in common carp (Cyprinus carpio L.). Comp. Biochem. Physiol. 83C, 179-184.

Daoust, P.-Y., and Ferguson, H. W. (1984). The pathology of chronic ammonia toxicity in rainbow trout, Salmo gairdneri Richardson. J. Fish Dis. 7, 199-205.
Davenport, J., and Sayer, M. D. J. (1986). Ammonia and urea excretion in the amphibious teleost Blennius pholis (L.) in sea-water and in air. Comp. Biochem. Physiol. 84A, 189-194.

Evans, D. H., and Cameron, J. N. (1986). Gill ammonia transport. J. Exp. Zool. 239, 17-23.

Evans, D. H., Piermarini, P. M., and Choe, K. P. (2005). The multifunctional fish gill: dominant site of gas exchange, osmoregulation, acid-base regulation, and excretion of nitrogenous waste. Physiol. Rev. 85, 97-177.

Fan, P., and Szerb, J. C. (1993). Effects of ammonium ions on synaptic transmission and on responses to quisqualate and $\mathrm{N}$-methyl-D-aspartate in hippocampal CA1 pyramidal neurons in vitro. Brain Res. 632, 225-231.

Felipo, V., and Butterworth, R. F. (2002). Neurobiology of ammonia. Prog. Neurobiol. 67, 259-279.

Ferguson, H.W., Morrison, D., Ostland, V. E., Lumsden, J., and Byrne, P. (1992). Responses of mucus-producing cells in gill disease of rainbow trout (Oncorhynchus mykiss). J. Comp. Pathol. 106, 255-265.

Ferri, D., Mazzone, A., Liquori, G. E., Cassano, G., Svelto, M., and Calamita G. (2003). Ontogeny, distribution, and possible functional implications of an unusual aquaporin, $\mathrm{AQP} 8$, in mouse liver. Hepatology 38, 947-957.

Fines, G. A., Ballantyne, J. S., and Wright, P. A. (2001). Active urea transport and an unusual basolateral membrane composition in the gills of a marine elasmobranch. Am. J. Physiol. 280 R16-R24.

Flessner, M. F., Wall. S. M., and Knepper, M. D. (1991). Permeability of rat collecting duct segments to $\mathrm{NH}_{3}$ and $\mathrm{NH}_{4}^{+}$ . Am. J. Physiol. 260, F264-F272.

French, C. J., Mommsen, T. P., and Hochachka, P. W. (1981). Amino acid utilization in isolated hepatocytes from rainbow trout. Eur. J. Biochem. 113, 311-317.

Frick, N. T., and Wright, P. A. (2002) Nitrogen metabolism and excretion in the mangrove killifish Rivulus marmoratus. II. Significant ammonia volatilization in a teleost during airexposure. J. Exp. Biol. 205, 91-100.

Gena, P., Fanelli, E., Brenner, C., Svelto, M., and Calamita, G. (2009). News and views on mitochondrial water transport. Front. Biosci. 1, 352-361.

Goldstein, L., Claiborne, J. B., and Evans, D. E. (1982). Ammonia excretion by the gills of two marine teleost fish: the importance of $\mathrm{NH}_{4}^{+}$permeance. J. Exp. Zool. 219, 395-397.

Gonzalez, R. J., and McDonald, D. G. (1994). The relationship between oxygen uptake and ion loss in fish from diverse habitats. J. Exp. Biol. 190, 95-108.

Görg, B., Morwinsky, A., Keitel, V., Quartskhava, N., Schrör, K., and Häussinger, D. (2010). Ammonia triggers exocytotic release of L-glutamate from cultured rat astrocytes. Glia 58 , 691-705.

Graham, J. B. (1997). Air-Breathing Fishes. San Diego: Academic Press.

Han, K. H., Croker, B. P. Clapp, W. L., Werner, D., Sahni, M., Kim, J., Kim, H. Y., Handlogten, M. E., and Weiner, I. D. (2006). Expression of the ammonia transporter, RhC glycoprotein, in normal and neoplastic human kidney. J. Am. Soc. Nephrol. 17, 2670-2679.

Häussinger, D., and Görg, B. (2010). Interaction of oxidative stress, astrocyte swelling and cerebral ammonia toxicity. Curr. Opin. Clin. Nutr. Metab. Care 13, 87-92.

Häussinger, D., and Schliess, F. (2008). Pathogenetic mechanisms of hepatic encephalopathy. Gut 57, 1156-1165.

Hazel, J. R., and Landrey, S. R. (1988). The course of thermal adaptation in plasma membranes of trout kidney. I. Headgroup composition. Am. J. Physiol. 255, R622-R627.

He, Y., Hakvoort, T. B. M., Kohler, S. E., Vermeulen, J.L. M., de Waart, D. R., de Theije, C., ten Have, G. A. M., van Eikl, H. M. H., Kunne, C., Labruyere, W. T. Houten, S. M., Sokolovic, M., Ruijter, J. M., Deutz, N. E. P., and Lamers, W. H. (2010). Glutamine synthetase in muscle is required for glutamine production during fasting and extrahepatic ammonia detoxification. J. Biol. Chem. 285, 9516-9524.

Hermenegildo, C., Marcaida, G., Montoliu, C., Grisolia, S., Minana, M., and Felipo, V. (1996). NMDA receptor antagonists prevent acute ammonia toxicity in mice. Neurochem. Res. 21 , 1237-1244.

Hernández-Fonseca, K., CardenasRodriguez, N., Pedraza-Chaverri, J., and Massieu, L. (2008). Calciumdependent production of reactive oxygen species is involved in neuronal damage induced during glycolysis inhibition in cultured hippocampal neurons. J. Neurosci. Res. 86, 1768-1780.

Holm, L. M., Jahn, T. P., Moller, A. L. B., Schjoerring, J. K., Ferri, D., Klaerke, D. A., and Zeuthen, T. (2005). $\mathrm{NH}_{3}$ and $\mathrm{NH}_{4}^{+}$permeability in aquaporinexpressing Xenopus oocytes. Pflugers Arch. 450, 415-428.

Houlihan, D. F., Carter, C. G., and McCarthy, I. D. (1995). "Protein turnover in animals," in Nitrogen Metabolism and Excretion, eds P. J. 
Walsh and P. Wright (Boca Raton, FL: CRC Press), 307-395.

Huang, C. H., and Peng, J. (2005). Evolutionary conservation and diversification of Rh family genes and proteins. Proc. Natl. Acad. Sci. U.S.A. 102, 15512-15517.

Hung, C. Y. C., Nawata, C. M., Wood, C. M., and Wright, P. A. (2008). Rhesus glycoprotein and urea transporter genes are expressed in early stages of development of rainbow trout (Oncorhynchus mykiss). J. Exp. Zool. 309A, 262-268.

Hung, C. Y. C., Tsui, K. N. T., Wilson, J. M., Nawata, C. M., Wood, C. M., and Wright, P.A. (2007). Rhesus glycoprotein gene expression in the mangrove killifish Kryptolebias marmoratus exposed to elevated environmental ammonia levels and air. J. Exp. Biol. 210, 2419-2429.

Ip, Y. K., and Chew, S. F. (2010). "Nitrogen metabolism and excretion during aestivation," in Progress in Molecular and Subcellular Biology, Vol. 49, Aestivation Molecular and Physiological Aspects, eds C. A. Navas and J. E. Carvalho (Berlin/Heidelberg: Springer-Verlag), 63-94.

Ip, Y. K., Chew, S. F., Leong, I. W. A., Jin, Y., and Wu, R. S. S. (2001a). The sleeper Bostrichthys sinensis (Teleost) stores glutamine and reduces ammonia production during aerial exposure. $J$. Comp. Physiol. B 171, 357-367.

Ip, Y. K., Chew, S. F., and Randall, D. J. (2001b). "Ammonia toxicity, tolerance and excretion," in Fish Physiology, Vol. 19, Nitrogen Excretion, eds P. A. Wright and P.M.Anderson (New York: Academic Press), 109-148.

Ip, Y. K., Lim, C. B., Chew, S. F., Wilson, J. M., and Randall, D. J. (2001c). Partial amino acid catabolism leading to the formation of alanine in Periophthalmodon schlosseri (mudskipper): a strategy that facilitates the use of amino acids as an energy source during locomotory activity on land. J. Exp. Biol. 204, 1615-1624.

Ip, Y. K., Chew, S. F., and Randall, D. J. (2004a). Five tropical fishes, six different strategies to defend against ammonia toxicity on land. Physiol. Biochem. Zool. 77, 768-782.

Ip, Y. K., Chew, S. F., Wilson, J. M., and Randall, D. J. (2004b). Defences against ammonia toxicity in tropical fishes exposed to high concentrations of environmental ammonia: a review. J. Comp. Physiol. B 174, 565-575.

Ip, Y. K., Lim, C. K., Lee, S. L. M., Wong, W. P., and Chew,S.F. (2004c).Postprandial increases in nitrogenous excretion and urea synthesis in the giant mudskipper Periophthalmodon schlosseri. J. Exp. Biol. 207, 3015-3023.
Ip, Y. K., Randall, D. J., Kok, T. K. T., Bazarghi, C., Wright, P. A., Ballantyne, J. S., Wilson, J. M., and Chew, S. F. (2004d). The mudskipper Periophthalmodon schlosserifacilitates active $\mathrm{NH}_{4}^{+}$excretion by increasing acid excretion and having a low $\mathrm{NH}_{3}$ permeability in the skin. J. Exp. Biol. 207, 787-801.

Ip, Y. K., Subaidah, R. M., Liew, P. C., Loong, A. M., Hiong, K. C., Wong, W. P., and Chew, S. F. (2004e). The African catfish Clarias gariepinus does not detoxify ammonia to urea or amino acids during ammonia loading but is capable of excreting ammonia against an inwardly driven ammonia concentration gradient. Physiol. Biochem. Zool. 77, 255-266.

Ip, Y. K., Tay, A. S. L., Lee, K. H., and Chew, S. F. (2004f). Strategies adopted by the swamp eel Monopterus albus to survive in high concentrations of environmental ammonia. Physiol. Biochem. Zool. 77, 390-405.

Ip, Y. K., Lee, C. Y., Chew, S. F., Low, W. P., and Peng, K. W. (1993). Differences in the responses of two mudskippers to terrestrial exposure. Zool. Sci. 10, 511-519.

Ip, Y. K., Leong, M. W. F., Sim, M. Y., Goh, G. S., and Chew, S. F. (2005a). Chronic and acute ammonia toxicity in mudskippers, Periophthalmodon schlosseri and Boleophthalmus boddaerti: brain ammonia and glutamine contents, and effects of methionine sulfoximine and MK801. J. Exp. Biol. 208, 1993-2004.

Ip, Y. K., Peh, B. K., Tam, W. L., Lee, S. L. M., and Chew, S. F. (2005b). Changes in salinity and ionic compositions can act as environmental signals to induce a reduction in ammonia production in the African lungfish Protopterus dolloi. J. Exp. Zool. 303A, 456-463.

Ip, Y. K., Peh, B. K., Tam, W. L., Wong, W. P., and Chew, S. F. (2005c). Effects of intra-peritoneal injection with $\mathrm{NH}_{4} \mathrm{Cl}$, urea or $\mathrm{NH}_{4} \mathrm{Cl}+$ urea on nitrogen excretion and metabolism in the African lungfish Protopterus dolloi. J. Exp. Zool. 303A, 272-282.

Ip, Y. K., Loong, A. M., Ching, B., Tham, G. H. Y., Wong, W. P., and Chew, S. F. (2009). The freshwater Amazonian stingray, Potamotrygon motoro, up-regulates glutamine synthetase activity and protein abundance, and accumulates glutamine when exposed to brackish (15\%o) water. J. Exp. Biol. 212, 3828-3836.

Iwata, K., and Deguichi, M. (1995). Metabolic fate and distribution of ${ }^{15} \mathrm{~N}$-ammonia in an ammonotelic amphibious fish, Periophthalmus modestus, following immersion in ${ }^{15} \mathrm{~N}$-ammonium sulphate: a long term experiment. Zool. Sci. 12, 175-184.
Iwata, K., Kajimura, M., and Sakamoto, T. (2000). Functional ureogenesis in the gobiid fish Mugilogobius abei. J. Exp. Biol. 203, 3703-3715.

Janssens, P. A., and Cohen, P. P. (1968). Biosynthesis of urea in the estivating African lungfish and in Xenopus laevis under conditions of water shortage. Comp. Biochem. Physiol. 24, 887-898.

Jayakumar,A.R., Rama Rao, K.V., Murthy, Ch. R. K., and Norenberg, M. D. (2006). Glutamine in the mechanism of ammonia-induced astrocyte swelling. Neurochem. Int. 48, 623-628.

Jayakumar, A. R., Rama Rao, K. V., Schousboe, A., and Norenberg, M. D. (2004). Glutamine-induced free radical production in cultured astrocytes. Glia 46, 296-301.

Jow, L.Y., Chew, S. F., Lim, C. B., Anderson, P. M., and Ip,Y.K. (1999). The marble goby Oxyeleotrismarmoratus activates hepatic glutamine synthetase and detoxifies ammonia to glutamine during air exposure. J. Exp. Biol. 202, 237-245.

Karlsson, A., Eliason, E. J., Mydland, L. T., Farrell, A. P., and Kiessling, A. (2006). Postprandial changes in plasma free amino acid levels obtained simultaneously from the hepatic portal vein and the dorsal aorta in rainbow trout (Oncorhynchus mykiss). J. Exp. Biol. 209, 4885-4894.

Kikeri, D., Sun, A., Zeidel, M. L., and Hebert, S. C. (1989). Cell membranes impermeable to $\mathrm{NH}_{3}$. Nature 339 , 478-480.

King, P.A., and Goldstein, L. (1983). Renal ammoniagenesis and acid excretion in the dogfish, Squalus acanthias. Am. J. Physiol. 245, R581-R589.

Kleiner, D. (1992). " $\mathrm{NH}_{4}^{+}$transport systems," in Alkali Cation Transport Systems in Prokaryotes, ed. Bakker, E.P. (Boca Raton: CRC Press), 379-396.

Kok, T. W. K., Lim, C. B., Lam, T. J., and Ip, Y. K. (1998). The mudskipper Periophthalmodon schlosseri respires more efficiently on land than in water and vice versa for Boleophthalmus boddaerti. J. Exp. Zool. 280, 86-90.

Kosenko, E., Kaminski, Y., Lopata, O., Muravyov, N., and Felipo, V. (1999). Blocking NMDA receptors prevents the oxidative stress induced by acute ammonia intoxication. Free Radic Biol. Med. 26, 1369-1374.

Kosenko, E., Kaminsky, Y., Stavroskaya, I. G., and Felipo, V. (2000). Alteration of mitochondrial calcium homeostasis by ammonia-induced activation of NMDA receptors in rat brain in vivo Brain Res. 880, 139-146.

Krogmann, D. W., Jagendorf, A. T., and Avron, M. (1959). Uncouplers of spinach chloroplast phostosynthetic phosphorylation. Plant Physiol. 34 272-277.
Lande, M. B., Donovan, J. M., and Zeidel, M.L. (1995). The relationship between membrane fluidity and permeabilities to water, solute, ammonia, and protons. J. Gen. Physiol. 106, 67-84.

LaNoue, K. F., and Schoolwerth, A. C. (1979). Metabolite transport in mitochondria. Annu. Rev. Biochem. 48, 871-922.

Lee, W. K., Bork, U., Gholamrezaei, F., and Thevenod, F. (2005). $\mathrm{Cd}^{2+}$-induced cytochrome $\mathrm{c}$ release in apoptotic proximal tubule cells: role of mitochondrial permeability transition pore and $\mathrm{Ca}^{2+}$ uniporter. Am. J. Physiol. Renal Physiol. 288, F27-F39.

Leech, A. R., Goldstein, L., Cha, C. J., and Goldstein, J. M. (1979). Alanine biosynthesis during starvation in skeletal muscle of the spiny dogfish, Squalus acanthias. J. Exp. Zool. 207, 73-90.

Lemberg,A., and Fernandez, M.A. (2009). Hepatic encephalopathy, ammonia, glutamate, glutamine and oxidative stress. Ann. Hepatol. 8, 95-102.

Lichter-Konecki, U., Mangin, J. M., Gordish-Dressman, H., Hoffman, E. P., and Gallo, V. (2008). Gene expression profiling of astrocytes from hyperammonemic mice reveals altered pathways for water and potassium homeostasis in vivo. Glia 56, 365-377.

Lim, C. B., Anderson, P. M., Chew, S. F., and Ip, Y. K. (2001). Reduction in the rates of protein and amino acid catabolism to slow down the accumulation of endogenous ammonia: a strategy potentially adopted by mudskippers (Periophthalmodon schlosseri and Boleophthalmus boddaerti) during aerial exposure in constant darkness. J. Exp. Biol. 204, 1605-1614.

Lim, C. K., Chew, S. F., Tay, A. S. L., and Ip, Y. K. (2004a). Effects of peritoneal injection of $\mathrm{NH}_{4} \mathrm{HCO}_{3}$ on nitrogen excretion and metabolism in the swamp eel Monopterus albus increased ammonia excretion with an induction of glutamine synthetase activity. J. Exp. Zool. 301A, 324-333.

Lim, C K, Wong, W. P., Lee, S. M. L., Chew, S. F., and Ip, Y. K. (2004b). The ammonotelic African lungfish Protopterus dolloi increases the rate of urea synthesis and becomes ureotelic after feeding. J. Comp. Physiol. B 174, 555-564.

Lin, H., and Randall, D. J. (1995). "Proton pump in fish gills," in Fish Physiology, Vol. 14, Cellular and Molecular Approaches to Fish Ionic Regulation, eds C. M. Wood and T. J. Shuttleworth (Orlando: Academic Press), 229-255.

Lindley, T. E., Scheiderer, C. L., Walsh, P. J., Wood, C. M., Bergman, H. L., Bergman, A. L., Laurent, P., Wilson, P. and Anderson, P. M. (1999). Muscle as 
the primary site of urea cycle enzyme activity in an alkaline lake-adapted tilapia, Oreochromis alcalicus grahami. J. Biol. Chem. 274, 29858-29861.

Litwiller, S. L., O'Donnell, M. J. O., and Wright, P. A. (2006). Rapid increase in the partial pressure of $\mathrm{NH}_{3}$ on the cutaneous surface of air-exposed mangrove killifish, Rivulus marmoratus. J. Exp. Biol. 209, 1737-1745.

Loong, A. M., Hiong, K. C., Lee, S. L. M., Wong, W. P., Chew, S. F., and Ip, Y. K. (2005). Ornithine-urea cycle and urea synthesis in African lungfishes, Protopterus aethiopicus and Protopterus annectens, exposed to terrestrial conditions for 6 days. J. Exp. Zool. 303A, 354-365.

Loong, A. M., Tan, J. Y. L., Wong, W. P., Chew, S. F., and Ip, Y.K. (2007). Defense against environmental ammonia toxicity in the African lungfish, Protopterus aethiopicus: bimodal breathing, skin ammonia permeability and urea synthesis. Aquat. Toxicol. 85, 76-86.

Low, W. P., Ip, Y. K., and Lane, D. J. W. (1990). A comparative study of the gill morphometry in three mudskippers - Periophthalmus chrysospilos, Boleophthalmus boddaerti and Periophthalmus schlosseri. Zool. Sci. 7, 29-38.

Low, W. P., Lane, D. J. W., and Ip, Y. K. (1988). A comparative study of terrestrial adaptations in three mudskippers - Periophthalmus chrysospilos, Boleophthalmus boddaerti and Periophthalmodon schlosseri. Biol. Bull. $175,434-438$.

Madara, J. L. (1998). Regulation of the movement of solutes across tight junctions. Annu. Rev. Physiol. 60, 143-159.

Maetz, J. (1973). $\mathrm{Na}^{+} / \mathrm{NH}_{4}^{+}, \mathrm{Na}^{+} / \mathrm{H}^{+}$ exchanges and $\mathrm{NH}_{3}$ movement across the gill of Carassius auratus. J. Exp. Biol. 58, 255-273.

Marcaggi, P., and Coles, J. A. (2001). Ammonium in nervous tissue: transport across cell membranes, fluxes from neurons to glial cells, and role in signaling. Prog. Neurobiol. 64, 157-183.

Marcaida, G., Felipo, V., Hermenegildo, C., Minana, M. D., and Grisolia, S. (1992). Acute ammonia toxicity is mediated by NMDA type of glutamate receptors. FEBS Lett. 296, 67-68.

Miñana, M. D., Hermenegildo, C., Llansola, M. Montoliu, C., Grisolia, S., and Felipo, V. (1996). Carnitine and choline derivatives containing a trimethylamine group prevent ammonia toxicity in mice and glutamate toxicity in primary cultures of neurons. $J$. Pharmacol. Exp. Ther. 279, 194-199.

Mitchell, P. (1979). Keilin's respiratory chain concept and its chemi- osmotic consequences. Science 206, 1148-1159.

Mommsen, T. P., Busby, E. R., von Schalburg, K. R., Evans, J. C., Osachoff, H. L., and Elliott, M. E. (2003). Glutamine synthetase in tilapia gastrointestinal tract: zonation, cDNA and induction by cortisol. Comp. Biochem. Physiol. 173B, 419-427.

Mommsen, T. P., and Walsh, P. J. (1989). Evolution of urea synthesis in vertebrates - the piscine connection. Science 243, 72-75.

Mommsen, T. P., and Walsh, P. J. (1991). "Urea synthesis in fishes: evolutionary and biochemical perspectives," in Biochemistry and Molecular Biology of Fishes, 1. Phylogenetic and Biochemical Perspectives, eds P. W. Hochachka and T. P. Mommsen (Amsterdam: Elsevier), 137-163.

Mommsen, T. P., and Walsh, P. J. (1992). Biochemical and environmental perspectives on nitrogen metabolism in fishes. Experientia 48, 583-593.

Moreira-Silva, J., Tsui, T. K. N. Coimbra, J., Vijayan, M. M., Ip, Y. K., and Wilson, J. M. (2010). Branchial ammonia excretion in the Asian weatherloach Misgurnus anguillicaudatus. Comp. Biochem. Physiol. 151C, 40-50.

Mouro-Chanteloup, I., Cochet, S., Chami, M., Genetet, S., Zidi-Yahiaoui, N, Engel, A., Colin, Y., Bertrand, O., and Ripoche, P. (2010). Functional reconstitution into liposomes of purified human RhCG ammonia channel. PLoS ONE 5, e8921. doi: 10.1371/ journal.pone.0008921.

Murray, B. W., Busby, E. R., Mommsen, T. P., and Wright, P. A. (2003). Evolution of glutamine synthetase in vertebrates: multiply glutamine synthetase genes expressed in rainbow trout (Oncorhynchus mykiss). J. Exp. Biol. 206, 1511-1521.

Nakada, T., Hoshjima, K., Esakl, M., Nagayoshi, S., Kawakami, K., and Hirose, S. (2007a). Localization of ammonia transporter Rcgl in mitochondria-rich cells of yolk sac, gill, and kidney of zebrafish and its ionic strength-dependent expression. Am. J. Physiol. 293, R1743-R1753.

Nakada, T., Westhoff, C. M., Kato, A., and Hirose, S. (2007b). Ammonia secretion from fish gills depends on a set of Rh proteins. FASEB J. 21, 1-8.

Nakhoul, N. L., Hering-Smith, K. S., Abdulnour-Nakhoul, S. M., and Hamm, L. L. (2001). Transport of $\mathrm{NH}_{3} / \mathrm{NH}_{4}^{+}$in oocytes expressing aquaporin-1. Am. J. Physiol. Renal Physiol. 281, F255-F263.

Nawata, C. M., Hung, C. C. Y., Tsui, T. K. N., Wilson, J. M., Wright, P. A., and Wood, C. M. (2007). Ammonia excretion in rainbow trout (Oncorhynchus mykiss): evidence for Rh glycoprotein and $\mathrm{H}^{+}$-ATPase involvement. Physiol. Genomics 31, 463-474.

Nawata, C. M., Wood, C. M., and O’Donnell, M. J. (2010).Functional characterization of Rhesus glycoproteins from an ammoniotelic teleost, the rainbow trout, using oocyte expression and SIET analysis. J. Exp. Biol. 213, 1049-1059.

Norenberg, M. D., and MartinezHernandez, A. (1979). Fine structural localization of glutamine synthetase in astrocytes of rat brain. Brain Res. 161, 303-310.

Norenberg, M. D., Ramma Rao, K.V., and Jayakumar, A. R. (2005). Mechanisms of ammonia-induced astrocyte swelling. Metab. Brain Dis. 20, 302-317.

Numata, M., Petrecca, K., Lake, N., and Orlowski, J. (1998). Identification of a mitochondrial $\mathrm{Na}^{+} / \mathrm{H}^{+}$exchanger. $J$. Biol. Chem. 273, 6951-6959.

Ott, P., and Larsen, F. S. (2004). Bloodbrain barrier permeability to ammonia in liver failure: a critical reappraisal. Neurochem. Int. 44, 185-198.

Peh, W.Y.X., Chew, S. F., Wilson, J. M., and Ip, Y. K. (2009). Branchial and intestinal osmoregulatory acclimation in the four-eyed sleeper, Bostrychus sinensis (Lacepede), exposed to seawater. Mar Biol. 156, 1751-1764.

Peng, K. W., Chew, S. F., Lim, C. B., Kuah, S. S. L., Kok, T. W. K., and Ip, Y. K. (1998) The mudskippers Periophthalmodon schlosseri and Boleophthalmus boddaerti can tolerate environmental $\mathrm{NH}_{3}$ concentration of 446 and $36 \mu \mathrm{M}$, respectively. Fish Physiol. Biochem. 19 59-69.

Pichili, V. B. R., Rama Rao, K. V., Jayakumar, A. R., and Norenberg, M. D. (2007). Inhibition of glutamine transport into mitochondria protects astrocytes from ammonia toxicity. Glia $55,801-809$.

Planelles, G. (2007). Ammonium homeostasis and human Rhesus glycoproteins. Nephron Physiol. 105, 11-17.

Pohl, P. (2004). Combined transport of water and ions through membrane channels. Biol. Chem. 385, 921-926.

Raichle, M. E., and Larson, K. B. (1981). The significance of the $\mathrm{NH}_{3} \mathrm{NH}_{4}^{+}$ equilibrium on the passage of ${ }^{15} \mathrm{~N}$ ammonia from blood to brain. A new regional residue detection model. Circ. Res. 48, 913-937.

Rama Rao, K. V., Jayakumar, A. R., and Norenberg, M. D. (2003). Induction of the mitochondrial permeability transition in cultured astrocytes by glutamine. Neurochem. Int. 43, 517-523.

Rama Rao, K. V., and Norenberg, M. D. (2007). Aquaporin-4 in hepatic encephalopathy. Metab. Brain Dis. 22, 265-275.
Randall, D. J., Ip, Y. K., Chew, S. F., and Wilson, J. W. (2004). Air breathing and ammonia excretion in the mudskipper, Periophthalmodon schlosseri Physiol. Biochem. Zool. 77, 783-788.

Randall, D. J., and Tsui, T. K. N. (2002). Ammonia toxicity in fish. Mar. Pollut. Bull. 45, 17-23.

Randall, D. J., Wilson, J. M., Peng, K. W., Kok, T. W. K., Kuah, S. S. L., Chew, S. F., Lam, T. J., and Ip, Y. K. (1999). The mudskipper, Periophthalmodon schlosseri, actively transports $\mathrm{NH}_{4}^{+}$against a concentration gradient. Am. J. Physiol. 46, R1562-R1567.

Randall, D. J., Wood, C. M., Perry, S. F., Bergman, H., Maloiy, G. M., Mommsen, T. P., and Wright, P. A. (1989). Urea excretion as a strategy for survival in a fish living in a very alkaline environment. Nature 337, 165-166.

Reddy, P. V. B., Rama Rao, K. V., and Norenberg, M. D. (2009). Inhibitors of the mitochondrial permeability transition reduce ammonia-induced cell swelling in cultured astrocytes. $J$. Neurosci. Res. 87, 2677-2685.

Rose, C. (2002). Increased extracellular brain glutamate in acute liver failure: decreased uptake or increased release? Metab. Brain Dis. 17, 251-261.

Rozemeijer, M. J. C., and Plaut, I. (1993). Regulation of nitrogen excretion of the amphibious blenniidae Alticus kirki (Guenther, 1868) during emersion and immersion. Comp. Biochem. Physiol. 104A, 57-62.

Sanderson, L. A., Wright, P. A., Robinson, J. W., Ballantyne, J. S., and Bernier, N. J. (2010). Inhibition of glutamine synthetase during ammonia exposure in rainbow trout indicates a high reserve capacity to prevent brain ammonia toxicity. J. Exp. Biol. 213, 2343-2353.

Saparov, S. M., Liu, K., Agre, P., and Pohl, P. (2007). Fast and selective ammonia transport by aquaporin-8. J. Biol. Chem. 282, 5296-5301.

Shih, T. H., Horng, J. L., Hwang, P. P., and Lin, L. Y. (2008). Ammonia excretion by the skin of zebrafish (Danio rerio) larvae. Am. J. Physiol. Cell Physiol. 295, C1625-C1632.

Smith, D. D. Jr., Ritter, N. M., and Campbell, J. W. (1983). Glutamine synthetase isozymes in elasmobranch brain and liver tissues. J. Biol. Chem. 262, 198-202.

Soria, L. R., Fanelli, E.,Altamura, N., Svelto, M., Marinelli, R. A., and Calamita, G. (2010). Aquaporin-8-facilitated mitochondrial ammonia transport. Biochem. Biophys. Res. Commun. 393, 217-221.

Steele, S. L., Yancey, P. H., and Wright, P. A. (2005). The little skate Raja erinacea exhibits an extrahepatic ornithine 
urea cycle in the muscle and modulates nitrogen metabolism during low-salinity challenge. Physiol. Biochem.Zool. 78, 216-226.

Tay, S. L. A., Chew, S. F., and Ip, Y. K. (2003). The swamp eel Monopterus albus reduces endogenous ammonia production and detoxifies ammonia to glutamine during aerial exposure. J. Exp. Biol. 206, 2473-2386.

Tay, Y. L., Loong, A. M., Hiong, K. C., Lee, S. J., Tng, Y. Y., Wee, N. L., Lee, S. M., Wong, W. P., Chew, S. F., Wilson, J. M., and Ip, Y. K. (2006). Active ammonia transport and excretory nitrogen metabolism in the climbing perch, Anabas testudineus, during 4 days of emersion or $10 \mathrm{~min}$ of forced exercise on land. J. Exp. Biol. 209, 4475-4489.

Thomas, R. C. (1984). Experimental displacement of intracellular $\mathrm{pH}$ and the mechanism of its subsequent recovery. J. Physiol. 354, 3-22.

Tng, Y. Y. M., Chew, S. F., Wee, N. L. J., Wong, F. K., Wong, W. P., Tok, C. Y., and Ip, Y. K. (2009). Acute ammonia toxicity and the protective effects of methionine sulfoximine on the swamp eel, Monopterus albus. J. Exp. Zool. 311A, 676-688.

Tng, Y. Y. M., Wee, N. L. J., Ip, Y. K., and Chew, S. F. (2008). Postprandial nitrogen metabolism and excretion in juvenile marble goby, Oxyeleotris marmorata (Bleeker, 1852). Aquaculture 284, 260-267.

Tok C. Y., Chew S. F., Peh, W.Y. X., Loong, A. M. Wong, W. P., and Ip Y. K. (2009). Glutamine accumulation and upregulation of glutamine synthetase activity in the swamp eel, Monopterus albus (Zuiew), exposed to brackish water. J. Exp. Biol. 212, 1248-1258.

Tsui, T. K. N., Randall, D. J., Chew, S. F., Jin, Y., Wilson, J. M., and Ip, Y. K. (2002). Accumulation of ammonia in the body and $\mathrm{NH}_{3}$ volatilization from alkaline regions of the body surface during ammonia loading and exposure to air in the weather loach Misgurnus anguillicaudatus. J. Exp. Biol. 205, 651-659.

Tsui, T. K. N., Randall, D. J., Hanson, L., Farrell, A. P., Chew, S. F., and Ip, Y. K. (2004). Dogmas and controversies in the handling of nitrogenous wastes: ammonia tolerance in the oriental weatherloach Misgurnus anguillicaudatus. J. Exp. Biol. 207, 1977-1983.

Twitchen, I. D., and Eddy, F. B. (1994). Effects of ammonia on sodium- balance in juvenile rainbow-trout Oncorhynchus mykiss Walbaum. Aquat. Toxicol. 30, 27-45.

van den Thillart, G., and van Raaji, M. (1995). "Endogenous fuels; noninvasive versus invasive," in Biochemistry and Molecular Biology of Fishes, Vol. 4, Metabolic Biochemistry, eds P. W. Hochachka and T. P. Mommsen (Amsterdam: Elsevier), 33-63.

Veauvy, C. M., McDonald, M. D., Van Audekerke, J., Vanhoutte, G., Van Camp, N., Van der Linden, A. T., and Walsh, P. J. (2005). Ammonia affects brain nitrogen metabolism but not hydration status in the Gulf toadfish (Opsanus beta). Aquat. Toxicol. 74, 32-46.

Walsh, P. J., Bergman, H. L., Narahara, A., Wood, C. M., Wright, P. A., Randall, D. J., Maina, J. N., and Laurent, P. (1993). Effects of ammonia on survival, swimming and activities of enzymes of nitrogen metabolism in the Lake Magadi tilapia Oreochromis alcalicus grahami. J. Exp. Biol. 180, 323-387.

Walsh, P. J., Danulat, E., and Mommsen, T. P. (1990). Variation in urea excretion in the gulf toadfish (Opsanus beta). Mar. Biol. 106, 323-328.

Walsh, P. J., Mayer, G. D., Medina, M., Bernstein, M. L., Barimo, J. F., and Mommsen, T. P. (2003). A second glutamine synthetase gene with expression in the gills of the Gulf toadfish (Opsanus beta). J. Exp. Biol. 206, 1523-1533.

Walsh, P. J., and Milligan, C. J. (1995). Effects of feeding on nitrogen metabolism and excretion in the gulf toadfish (Opsanus beta). J. Exp. Biol. 198, 1559-1566.

Walsh, P. J., and Smith, C. P. (2001). "Urea transport," in Fish Physiology, Vol. 20, Nitrogen Excretion, eds P. A. Wright and P.M.Anderson (New York: Academic Press), 279-307.

Walton, M. J., and Cowey, C. B. (1977). Aspects of ammoniagenesis in rainbow trout, Salmo gairdneri. Comp. Biochem. Physiol. 57, 143-149.

Webb, J. T., and Brown, G. W. Jr. (1976). Some properties and occurrence of glutamine synthetase in fish. Comp. Biochem. Physiol. 54B, 171-175.

Webb, J. T., and Brown, G. W. Jr. (1980). Glutamine synthetase: assimilatory role in liver as related to urea retention in marine Chondrichthyes. Science 208, 293-295.

Wee, N. L. J., Tng, Y. Y. M., Cheng, H. T., Lee, S. M. L., Chew, S. F., and Ip,
Y. K. (2007). Ammonia toxicity and tolerance in the brain of the African sharptooth catfish, Clarias gariepinus. Aquat. Toxicol. 82, 204-213.

Weihrauch, D., Wilkie, M. P., and Walsh, P. J. (2009). Ammonia and urea transporters in gills of fish and aquatic crustaceans. J. Exp. Biol. 212, 1716-1730.

Wicks, B. J., and Randall, D. J. (2002). The effect of feeding and fasting on ammonia toxicity in juvenile rainbow trout, Oncorhynchus mykiss. Aquat. Toxicol. 59, 71-82.

Wilkie, M. P. (1997). Mechanisms of ammonia excretion across fish gills. Comp. Biochem. Physiol. 118A, 39-50.

Wilkie, M. P. (2002). Ammonia excretion and urea handling by fish gills: present understanding and future research challenges. J. Exp. Zool. 293, 284-301.

Wilkie, M.P., and Wood, C.M. (1996). The adaptations of fish to extremely alkaline environments. Comp. Biochem. Physiol. 113B, 665-673.

Wilkie, M. P., Wright, P. A., Iwama, G. K., and Wood, C. M. (1993). The physiological responses of the Lahontan cutthroat trout (Oncorhynchus clarki henshawi), a resident of highly alkaline Pyramid Lake (pH 9.4), to challenge at pH 10. J. Exp. Biol. 175, 173-194.

Willard-Mack, C. L., Koehler, R. C. Hirata, T., Cork, L. C., Takahashi, H., Traystman, R. J., and Brusilow, S. W. (1996). Inhibition of glutamine synthetase reduces ammonia-induced astrocyte swelling in rat. Neuroscience 71, 589-599.

Wilson, J. M, Randall, D. J., Donowitz, M., Vogl, W. A., and Ip, Y. K. (2000). Immunolocalization of ion transport proteins to the mudskipper (Periophthalmodon schlosseri) branchial epithelium mitochondria-rich cells. J. Exp. Biol. 203, 2297-2310.

Wilson, J. M., Randall, D. J., Kok, T. W K., Vogl, W. A., and Ip, Y. K. (1999). Fine structure of the gill epithelium of the terrestrial mudskipper, Periophthalmodon schlosseri. Cell Tissue Res. 298, 345-356.

Wood, C. M., Bergman, H. L., Laurent, P., Maina, J. N., Narahara, A., and Walsh, P. J. (1994). Urea production, acid-base regulation and their interactions in the Lake Magadi tilapia a unique teleost adapted to a highly alkaline environment. J. Exp. Biol. 189, 13-36.
Wood,C. M., Kajimura, M., Mommsen, T. P., and Walsh, P. J. (2005). Alkaline tide and nitrogen conservation after feeding in an elasmobranch (Squalus acanthias). J. Exp. Biol. 208, 2693-2705.

Wright, P.A., Steele, S. L., Hvitema, A., and Bernier, N. J. (2007). Induction of four glutamine synthetase genes in brain of rainbow trout in response to elevated environmental ammonia. J. Exp. Biol. 210, 2905-2911.

Wright, P. A., and Wood, C. M. (2009). A new paradigm for ammonia excretion in aquatic animals: role of Rhesus (Rh) glycoproteins. J. Exp. Biol. 212, 2303-2312.

Wu, B., and Beitz, E. (2007). Aquaporins with selectivity for unconventional permeants. Cell. Mol. Life Sci. 64, 2413-2421.

Wu, C. (1963). Glutamine synthetase, intracellular localization in rat liver. Biochim. Biophys. Acta 77, 482-493.

Youngson, A., Cowey, C. B., and Walton, M. J. (1982). Some properties of serine pyruvate aminotransferase purified from liver of rainbow-trout Salmo gairdneri. Comp. Biochem. Physiol. 73B, 393-398.

Zwingmann, C., Flogel, U., Pfeuffer, J., and Leibfritz, D. (2000). Effects of ammonia exposition on glioma cells: changes in cell volume and organic osmolytes studied by diffusion-weighted and high-resolution NMR spectroscopy. Dev. Neurosci. 22, 463-471.

Conflict of Interest Statement: The authors declare that the research was conducted in the absence of any commercial or financial relationships that could be construed as a potential conflict of interest.

Received: 19 June 2010; paper pending published: 08 August 2010; accepted: 06 September 2010; published online: 04 October 2010.

Citation: Ip YK and Chew SF (2010) Ammonia production, excretion, toxicity, and defense in fish: a review. Front. Physio. 1:134. doi: 10.3389/fphys.2010.00134

This article was submitted to Frontiers in Aquatic Physiology, a specialty of Frontiers in Physiology

Copyright (c) 2010 Ip and Chew. This is an open-access article subject to an exclusive license agreement between the authors and the Frontiers Research Foundation, which permits unrestricted use, distribution, and reproduction in any medium, provided the original authors and source are credited. 